\title{
$\mathrm{PH} 9 \mathbf{9 4}$
}

\section{Los mamíferos del Plioceno y Pleistoceno de la Península Ibérica}

Bienvenido Martínez-Navarro | IPHES, Institut Català de Paleoecologia Humana i

Evolució Social, Àrea de Prehistòria, Universitat Rovira i Virgili (URV), ICREA

Sergio Ros-Montoya, María-Patrocinio Espigares | Dpto. de Ecología y Geología,

Facultad de Ciencias, Universidad de Málaga

Joan Madurell-Malapeira | Institut Català de Paleontologia Miquel Crusafont

Paul Palmqvist | Dpto. de Ecología y Geología, Facultad de Ciencias, Universidad

de Málaga

URL de la contribución <www.iaph.es/revistaph/index.php/revistaph/article/view/4203>

\section{RESUMEN}

España es el país con mayor número de yacimientos bien conservados, cantidad y calidad de fósiles de todo el continente europeo. Aquí se describe el patrimonio paleobiológico correspondiente al Plio-Pleistoceno (últimos 5,3 millones de años) registrado en los principales yacimientos con presencia de fósiles de grandes mamíferos de la Península Ibérica. Ningún otro país de nuestro entorno al norte del Mediterráneo ofrece mayores posibilidades para el estudio y disfrute de los registros paleontológicos del Plioceno y Pleistoceno. En este contexto destacan las principales cuencas sedimentarias como las de Besalú-Bañolas, Vallés, Calatayud-Teruel, o ya en el sur las cuencas intrabéticas, donde merece especial interés la de Baza y Guadix, con localidades emblemáticas como Baza 1 para el Plioceno, y como los yacimientos de Orce (Fuente Nueva 1 y 3, Venta Micena o Barranco León, entre otros) para el Pleistoceno inferior. También se hace referencia a otro tipo de yacimientos, como son los maares volcánicos pliocénicos del Camp dels Ninots en Cataluña, o el de las Higueruelas en la Mancha, a las terrazas fósiles de los grandes ríos peninsulares, así como a los extraordinarios registros kársticos, donde destaca el de Atapuerca en Burgos. Afortunadamente, este patrimonio es ya muy conocido y estudiado, y está publicado en las mejores revistas científicas mundiales. Sin embargo, salvo en el caso puntual de Atapuerca, su divulgación no ha llegado todavía a calar en el gran público, y su explotación cultural y turística necesita de un fuerte impulso en años venideros.

\section{Palabras clave}

España | Fósiles | Mamíferos terrestres | Patrimonio paleontológico | Península ibérica | Pleistoceno | Plioceno | Yacimientos | 


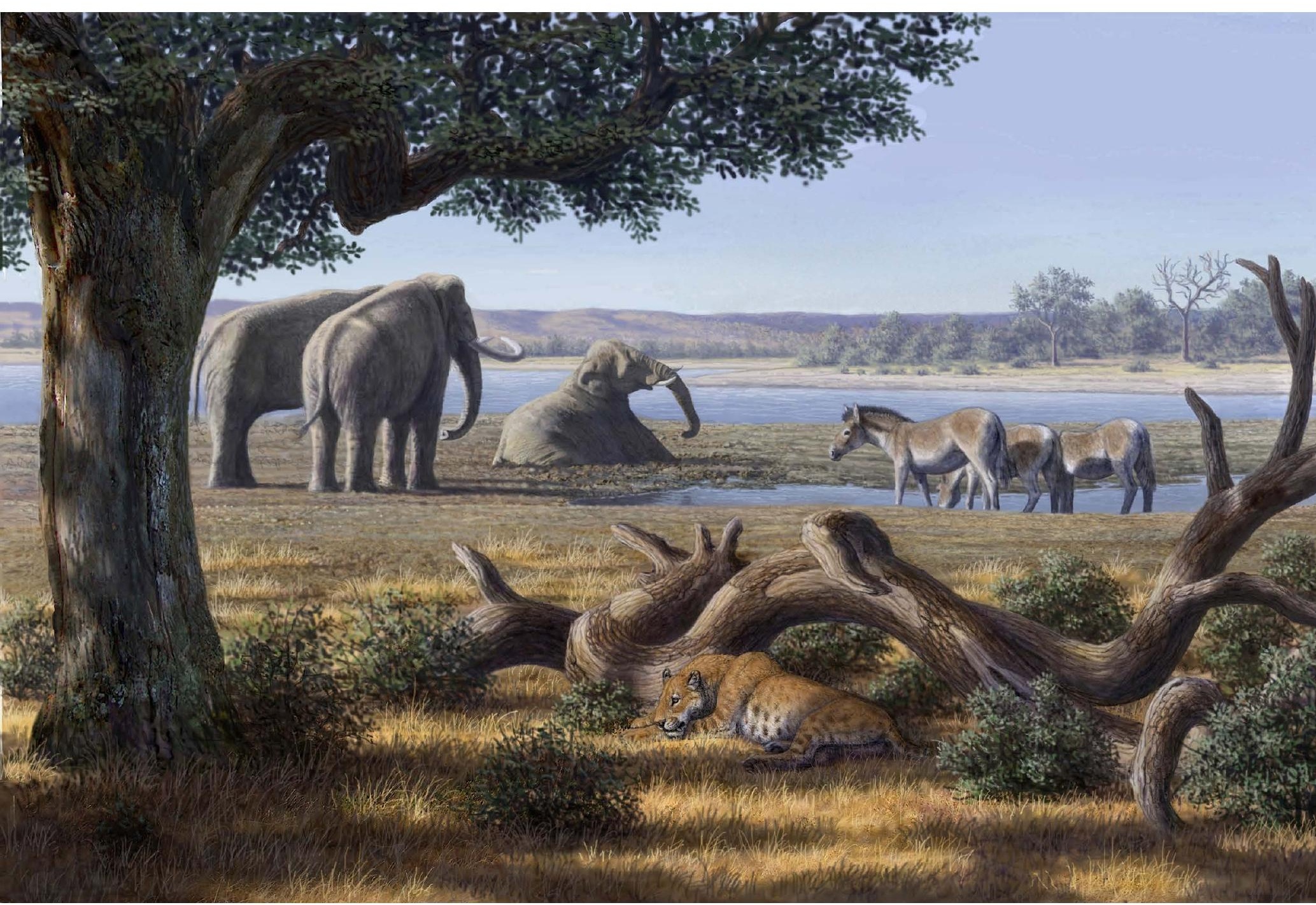

Reconstrucción del paleambiente registrado en el yacimiento de Venta Micena (Orce, Granada) | Ilustración Mauricio Antón 


\section{INTRODUCCIÓN}

Escudriñar el pasado es siempre un ejercicio detectivesco, pero si la excursión tiene lugar en el mundo de la paleontología y, en el caso que nos ocupa, en el de los vertebrados fósiles, especialmente los mamíferos terrestres, esta actividad se parece entonces mucho a la que realizan los forenses, pero contando con la gran ventaja de que los restos fósiles no huelen como los cadáveres y, además, suelen ser agradables al tacto. Ello permite tratarlos como objetos que se pueden estudiar y reestudiar permanentemente, mejorando el conocimiento que se tiene de ellos e incrementando así su valor patrimonial. Por esta causa, el discurso sobre el patrimonio paleontológico de los registros del Plio-Pleistoceno (últimos 5,33 millones de años) en las grandes cuencas sedimentarias de la geografía española, conjuntamente con las acumulaciones conservadas en los importantes sistemas kársticos existentes a lo largo de todas las cordilleras de nuestra Península, ha mejorado sustancialmente en los últimos años.

Las investigaciones sobre paleontología de vertebrados comenzaron a desarrollarse en España, especialmente después de la Guerra Civil, gracias a los trabajos y al ímpetu, en momentos muy difíciles para el país, de los profesores Miquel Crusafont, José F. de Villata y Jaume Truyols. Especialmente se centraron en un principio en el Mioceno catalán, en la cuenca del Vallés-Penedés, pero a partir de ahí y gracias al extraordinario registro de la Península, ampliaron sus investigaciones hacia el Plioceno y el Pleistoceno. Debido al enorme patrimonio de la Península Ibérica, desde que comenzaron a desarrollarse las ciencias del pasado en nuestro país, además de los tres paleontólogos arriba citados, son muchos los científicos que han contribuido con sus ideas y su trabajo en los yacimientos paleontológicos y arqueológicos a lo largo de todo el territorio; todos ellos, de una $u$ otra manera, han incidido en el desarrollo de estas ciencias, aportando conocimientos y nuevas interpretaciones sobre la geología, la paleontología, la arqueología, las técnicas de restauración de los fósiles, la museología, etc. Gracias a ello, hoy, en el año 2018, la paleontología española y, en este caso concreto, la que se ocupa del Plio-Pleistoceno, cuenta con uno de los discursos científicos más sólidos para la interpretación de los ecosistemas continentales de toda Europa.

Esta revisión se va a restringir al Plioceno, época geológica que comienza hace 5,3 millones de años y finaliza hace 2,6 millones de años, y al Pleistoceno, que empieza cuando acaba el Plioceno y finaliza hace unos 10.000 años, cuando entramos en el Holoceno, la época en la que todavía vivimos.

La Península Ibérica, al igual que las otras dos penínsulas meridionales de Europa, la Itálica y la Balcánica, presenta una serie de cuencas continentales Neógeno-Cuaternarias, especialmente bien representadas en el borde 
Mediterráneo y en el interior de las cordilleras Ibérica y Bética. Las principales cuencas son, de norte a sur, las de Besalú-Banyoles, Vallés-Penedés, Calatayud-Teruel, Guadix-Baza y Granada. También son importantes los yacimientos en las terrazas cuaternarias de los grandes ríos y sus afluentes, que abarcan desde el Pleistoceno inferior hasta el Holoceno. Son de destacar igualmente las importantes acumulaciones de fósiles en yacimientos ligados a cuencas situadas en complejos volcánicos. Son las acumulaciones situadas en maares, que son lagunas localizadas en las depresiones formadas en el interior de cráteres fósiles. En la Península corresponden especialmente al Plioceno superior, como el del Camp dels Ninots en el maar de Caldas de Malavella, Gerona (CAMPENY VALL-LLOSERA; GÓMEZ DE SOLER, 2010), o los registros de las Higueruelas en Alcolea de Calatrava, Ciudad Real (SEQUEIROS, 2010 y referencias incluidas).

A este registro hay que sumar los importantes rellenos kársticos localizados a lo largo de toda la Península, desde los famosos yacimientos de Atapuerca en Burgos (CARBONELL; BERMÚDEZ DE CASTRO; PARÉS et ál., 2008), que no necesitan presentación, a todos los registros en cuevas que bordean el arco Mediterráneo desde Cataluña, como las simas del Macizo del Garraf en Barcelona (por ejemplo, Cova del Gegant, DAURA, SANZ, SOBIRÁ et ál., 2005), pasando por las cuevas valencianas, como ocurre con los rellenos de Casablanca en Almenara, el Tossal de la Font en Villafamés (GUSI; CARBONELL; ESTEVEZ et ál., 1982), las Picarazas entre Chelva y Andilla (VICENTE GABARDA; MARTÍNEZ VALLE; GUILLEM CALATAYUD et ál., 2016) o Bolomor en Tavernes de la Valldigna (SAÑUDO; BLASCO; FERNÁNDEZ PERIS, 2016), a las murcianas como Cueva Victoria en Cartagena (MARTÍNEZ-NAVARRO; PALMQVIST; SHABEL et ál., 2008; FERRÀNDEZ-CAÑADELL; RIBOT; GIBERT, 2014), Quibas en Abanilla (ALBA; CARLOS-CALERO; MANCHEÑO et ál., 2011) o la Sima de las Palomas en Torre Pacheco (WALKER; GIBERT; LÓPEZ et ál., 2008), a las numerosas cuevas andaluzas, como el karst de Moreda (BAILÓN, 1992), Cueva Horá en Darro (BOTELLA LÓPEZ, 1987) o la cueva de la Carihuela en Píñar (VEGA-TOSCANO; HOYOS; RUIZ-BUSTOS et ál., 1988) (las tres en Granada), el Boquete de Zafarraya en Alcaucín (Málaga) (BARROSO RUIZ, 2003), la Cueva del Ángel en Lucena (Córdoba) (BARROSO RUíZ; BOTELLA ORTEGA; CAPARRÓS et ál., 2011), el Chaparral en Villaluenga (Cádiz) (GILES PACHECHO; SANTIAGO PÉREZ; GUTIÉRREZ et ál., 2011), e incluso las famosas cuevas de Gibraltar (FINLAYSON; GILES PACHECO; RODRÍGUEZ-VIDAL et ál., 2006) que, aunque no se encuentran dentro del territorio administrado por España, sí están en Andalucía, y ya en la cornisa cantábrica los famosos yacimientos de Lezetxiki en Mondragón (Guipúzcoa) (ARRIOLABENGOA; IRIARTE; ARANBURU et ál., 2015), Altamira en Santillana del Mar (Cantabria) (MONTES; LASHERAS, DE LAS HERAS et ál., 2004), la cueva del Sidrón en el concejo de Piloña (Asturias) (ROSAS; MARTÍNEZ-MAZA; BASTIR et ál., 2006), o la cueva de Eirós, en Triacastela 
(Lugo) (STEELMAN; DE LOMBERA HERMIDA; VIÑAS VALLVERDÚ et ál., 2017).

En este trabajo vamos a destacar el espectacular registro de algunos yacimientos, como son especialmente los de la cuenca de Guadix-Baza, por la abundancia de localidades paleontológicas, con dimensiones kilométricas, distribuidos a lo largo de todo el Plio-Pleistoceno, así como por la excelente conservación y la elevada densidad de restos esqueléticos de las especies extintas que albergan, en especial los de especies de grandes mamíferos, aquellas con más de cinco kilogramos de masa corporal.

Las asociaciones de mamíferos fósiles varían a lo largo del tiempo, dependiendo de circunstancias como la evolución de los distintos grupos taxonómicos y los eventos de dispersión y/o extinción de las especies, produciéndose de esta manera cambios sucesivos en la composición de la fauna a lo largo de la historia de nuestro planeta, que se relacionan por lo general con cambios importantes en la climatología y/o la tectónica, y facilitan o impiden las dispersiones y el recambio faunístico. Así, durante el Plioceno y el Cuaternario ha tenido lugar varias veces la renovación de las asociaciones de especies presentes en Europa. En este contexto, la Península Ibérica atesora, muy probablemente, el mejor registro de tales sucesiones faunísticas en todo el continente.

Asimismo, durante el Pleistoceno inferior los homininos colonizaron por primera vez el continente europeo y, hoy por hoy, las evidencias más antiguas de su presencia se localizan en España, concretamente en Andalucía, en dos yacimientos de la cuenca de Baza y Guadix situados en las inmediaciones de Orce: Barranco León y Fuente Nueva-3, datados en casi 1,5 millones de años (MARTÍNEZ-NAVARRO; TURQ; AGUSTÍ et ál., 1997; OMS; PARÉS; MARTÍNEZ-NAVARRO et ál., 2000; TORO-MOYANO; MARTÍNEZNAVARRO; AGUSTí et ál., 2013; PALMQVIST; DUVAL; DIÉGUEZ et ál., 2016). Una cronología similar, también con presencia de industria lítica y marcas de actividad antrópica sobre los huesos, tiene el yacimiento kárstico de las Picarazas en la Comunidad Valenciana (VICENTE GABARDA; MARTÍNEZ VALLE; GUILLEM CALATAYUD et ál., 2016). El nivel TE9 de la Sima del Elefante de Atapuerca, donde también hay restos humanos, es ligeramente más reciente, datado en 1,2 millones de años (CARBONELL; BERMÚDEZ DE CASTRO; PARÉS et ál., 2008). Estas poblaciones humanas arcaicas son muy particulares, sobre todo teniendo en cuenta que debieron ser mucho más carnívoras que sus homólogas africanas. Fue precisamente esa misma adaptación al consumo de carne la que permitió el desarrollo de las enormes capacidades cognitivas del género humano en África, el continente natal de la humanidad, al satisfacer las elevadas demandas energéticas del tejido nervioso (en nuestra especie representa un $22 \%$ de la tasa metabólica basal), lo que también permitió a estos distantes antepasados 
europeos sobrevivir en las latitudes medias, con climas estacionales de veranos secos e inviernos fríos, donde durante la estación invernal había pocos recursos vegetales para consumir, contrariamente a lo que ocurre en los ecosistemas tropicales, donde la vegetación acostumbra a ser más exuberante durante casi todo el año. Por ello, sólo un recurso accesible durante todas las estaciones del año pudo ayudar a la supervivencia de unos homininos necesitados de altas dosis de energía obtenibles de la grasa animal (en especial el tuétano de los huesos) para combatir el hambre y el frío invernal, en tiempos donde aún no está documentado el uso del fuego, carne procedente del carroñeo de los cadáveres de grandes mamíferos cuya muerte vino ocasionada por los depredadores dominantes en estos ecosistemas del Pleistoceno inferior, como los tigres de dientes de sable, así como los animales muertos por otras causas, como enfermedades o accidentes.

En este contexto, los yacimientos del Plio-Pleistoceno de la Península Ibérica son claves, y en muchas ocasiones únicos, para estudiar cada una de las especies registradas desde una perspectiva paleobiológica, intentado interpretar cómo eran, qué tamaño tenían, cuáles eran sus características anatómicas y fisiológicas, cómo se comportaban, cómo se relacionaban entre ellas y con el medio, cuál era su tipo de alimentación y, sobretodo, cuál era el rol de estos homininos carroñeros en un escenario único y privilegiado en el continente europeo. Como se verá más adelante, la paleontología cuenta con una serie de herramientas para ofrecer luz sobre estos aspectos, normalmente muy elusivos, como el estudio tafonómico de las circunstancias en las que se generaron las acumulaciones de fósiles conservadas en los yacimientos, los enfoques ecomorfológicos y biomecánicos tendentes a poner de manifiesto a partir de la forma de los dientes y huesos sus dimensiones corporales y sus adaptaciones a un tipo particular de dieta o unos hábitos de locomoción, o los análisis geoquímicos de su composición, mediante isótopos estables y elementos traza, que permiten inferir el tipo de hábitat en el que se desenvolvían y diversos aspectos de su ecofisiología (PALMQVIST; MARTÍNEZ-NAVARRO; ARRIBAS, 1996; ARRIBAS; PALMQVIST; 1998; PALMQVIST; ARRIBAS, 2001; PALMQVIST; GRÖCKE; ARRIBAS et ál., 2003; PALMQVIST; PÉREZ-CLAROS; GRÖCKE et ál., 2008; PALMQVIST; PÉREZ-CLAROS; JANIS et ál., 2008).

El patrimonio paleobiológico español es tan rico e informativo que no podemos pasar por alto una relación cronológica del registro de fósiles en este paraíso singular de la paleontología en Europa.

\section{EL PLIOCENO}

El Plioceno se divide en inferior, que discurre entre 5,3 y aproximadamente 3,4-3,2 millones de años, y se llama Rusciniense en los registros conti- 


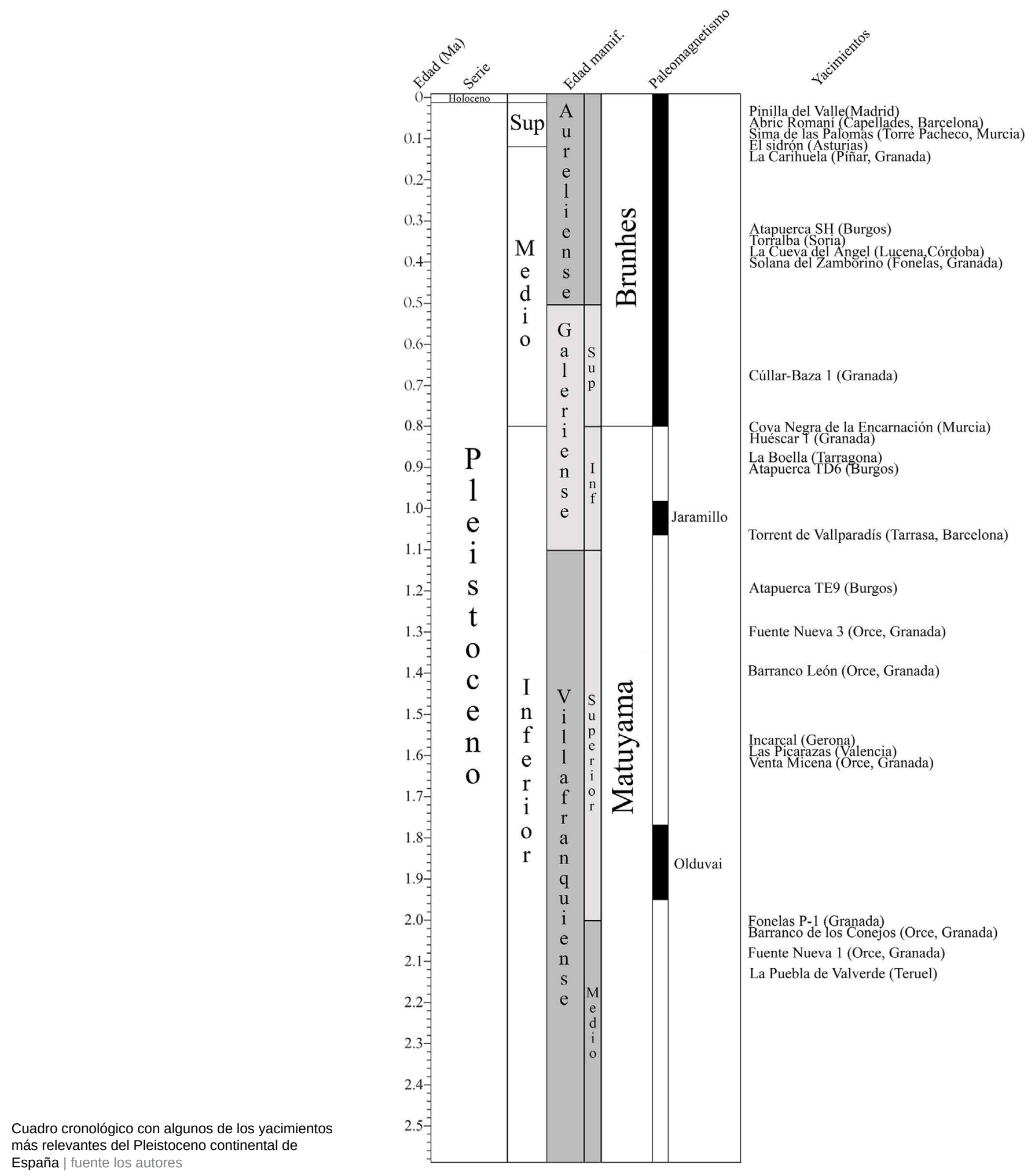

más relevantes del Pleistoceno continental de 


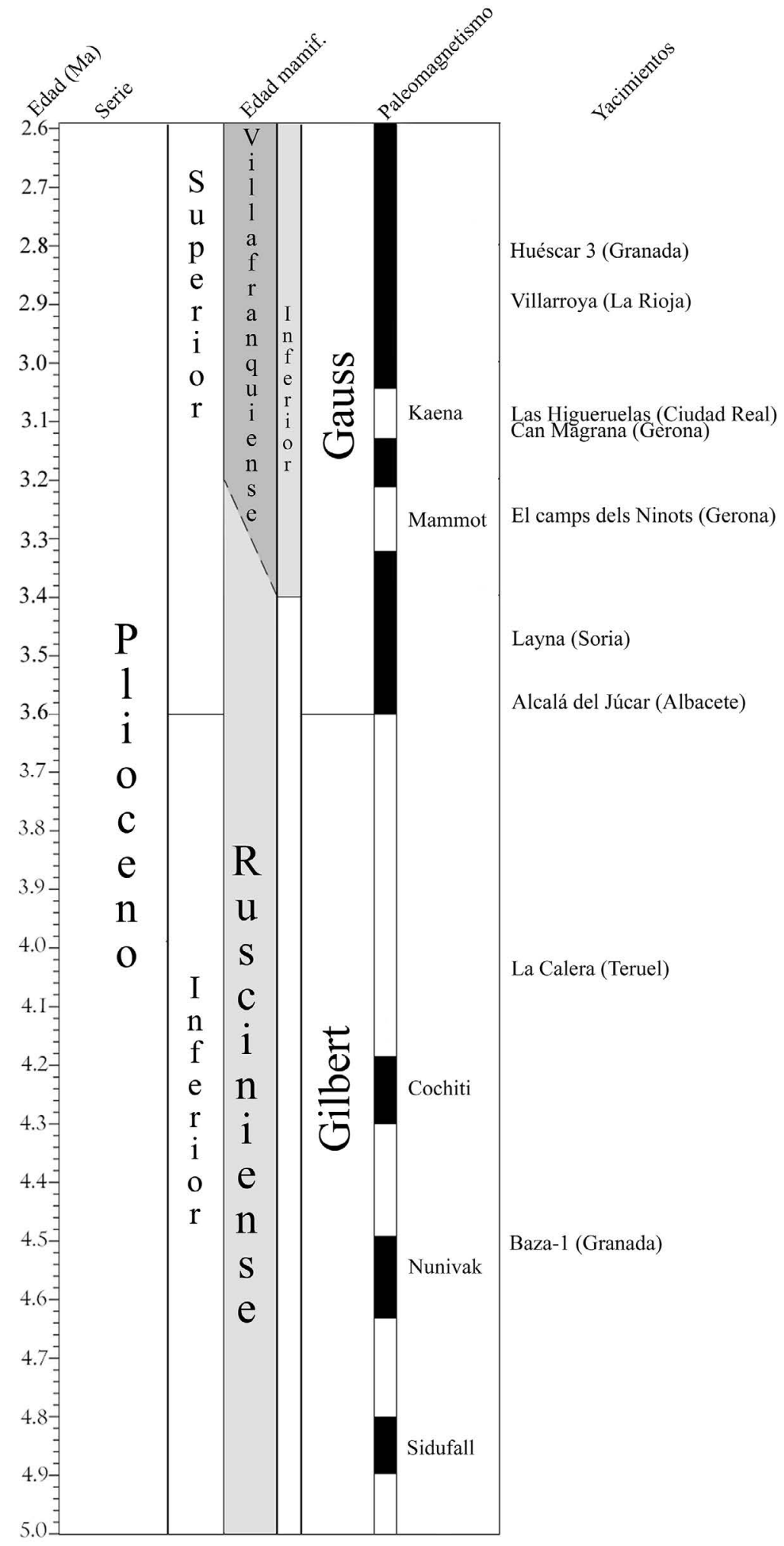


nentales, y superior, entre 3,4-3,2 y 2,6 millones años, correspondiente al Villafranquiense inferior, como se explicará más adelante.

Existe un importante vacío del registro fósil continental en Europa para el intervalo del Plioceno inferior. Esta carencia contrasta con la abundancia de datos conocidos para el Mioceno superior (11,2-5,3 millones de años) y para el Plioceno superior y la totalidad del Pleistoceno.

\section{EL PLIOCENO INFERIOR}

El Rusciniense se caracteriza por ser el resultado de un importante evento geológico, la apertura del contacto entre el Mediterráneo y el Atlántico a través del Estrecho de Gibraltar tras su cierre durante el Mesiniense, hace entre 6 y 5,3 millones de años, en el que la cuenca que separa Europa de África y de Asia había quedado cerrada, sin conexión al Atlántico ni al Índico; por ello, al ser deficitaria hidrológicamente, con una evaporación que supera al aporte por las precipitaciones, se había desecado totalmente en la mayoría de su extensión areal, lo que permitiría ir y venir andando desde el Magreb a la Península Ibérica sin cruzar ninguna barrera acuática. Una vez el Estrecho de Gibraltar se abrió, el Mediterráneo volvió a rellenarse con el agua procedente del Atlántico y se conformó una geografía parecida ya a la actual.

Al clima seco y frío del Mesiniense le sucedió un clima más cálido y húmedo en general, muy benigno en nuestras latitudes y con gran diversidad específica, con un nivel del mar más elevado que el actual. Las faunas del Rusciniense de la Península Ibérica se caracterizan por la conservación de diversos taxones de origen africano, especialmente roedores, como los múridos correspondientes al género Paraethomys, que llegaron a la Península y, tras quedarse aislados al norte del Estrecho, evolucionaron independientemente de sus parientes africanos. La subida del nivel de las aguas provocó, además, que la mayoría de las islas mediterráneas, unidas al continente durante el Mesiniense, quedaran totalmente aisladas, lo que permitió una evolución muy singular de las especies que las poblaban, generando en ocasiones seres aberrantes como la pequeña cabra rechoncha y paticorta de las islas baleares, con ojos frontalizados, un cerebro reducido e incisivos inferiores de crecimiento continuo, llamada Myotragus balearicus, que fue definida por la paleontóloga inglesa Dorothea Bate en 1909, especie que sobrevivió hasta el Holoceno, cuando fue extinguida por los primeros pobladores humanos de las islas, hace entre 4000 y 3500 años.

Actualmente, en Europa se conocen escasos yacimientos en cronologías ruscinienses con presencia de fauna de grandes mamíferos, como Megalo Emvolon en Grecia (ARAMBOURG; PIVETEAU, 1929; KOUFOS; KOSTOPOULOS, 1997), Malusteni en Rumania (RADULESCO; SAMSON; 
PETCULESCU et ál., 2003) y varias localidades en la zona del Rosellón en los Pirineos Orientales franceses, a los que hay que sumar los localizados en la Península Ibérica: La Calera en la cuenca de Calatayud-Teruel, Layna en Soria, Alcalá de Júcar en Albacete (ALBERDI; ALCALÁ, 1989-90; AZANZA; MENÉNDEZ, 1989-90; ALCALÁ; MORALES; MOYÁ-SOLÁ, 198990; MAZO, 1997), y especialmente el yacimiento de Baza-1, actualmente en fase de excavación (ROS-MONTOYA; MARTÍNEZ-NAVARRO; ESPIGARES et ál., 2017; PIÑERO; AGUSTí; OMS et ál., 2017). Esta última localidad merece una referencia especial, por el extraordinario estado de conservación en el que se encuentran los restos fósiles allí encontrados.

El yacimiento paleontológico de Baza-1 se sitúa en el Barranco de las Seguidillas-Cuesta del Francés, conocida en la zona como Las Arrodeas, a las afueras de la ciudad granadina de Baza. Este yacimiento fue localizado en el año 1996 por el primer firmante de estas líneas (Bienvenido Martínez Navarro) y los primeros trabajos comenzaron en el año 1999, al
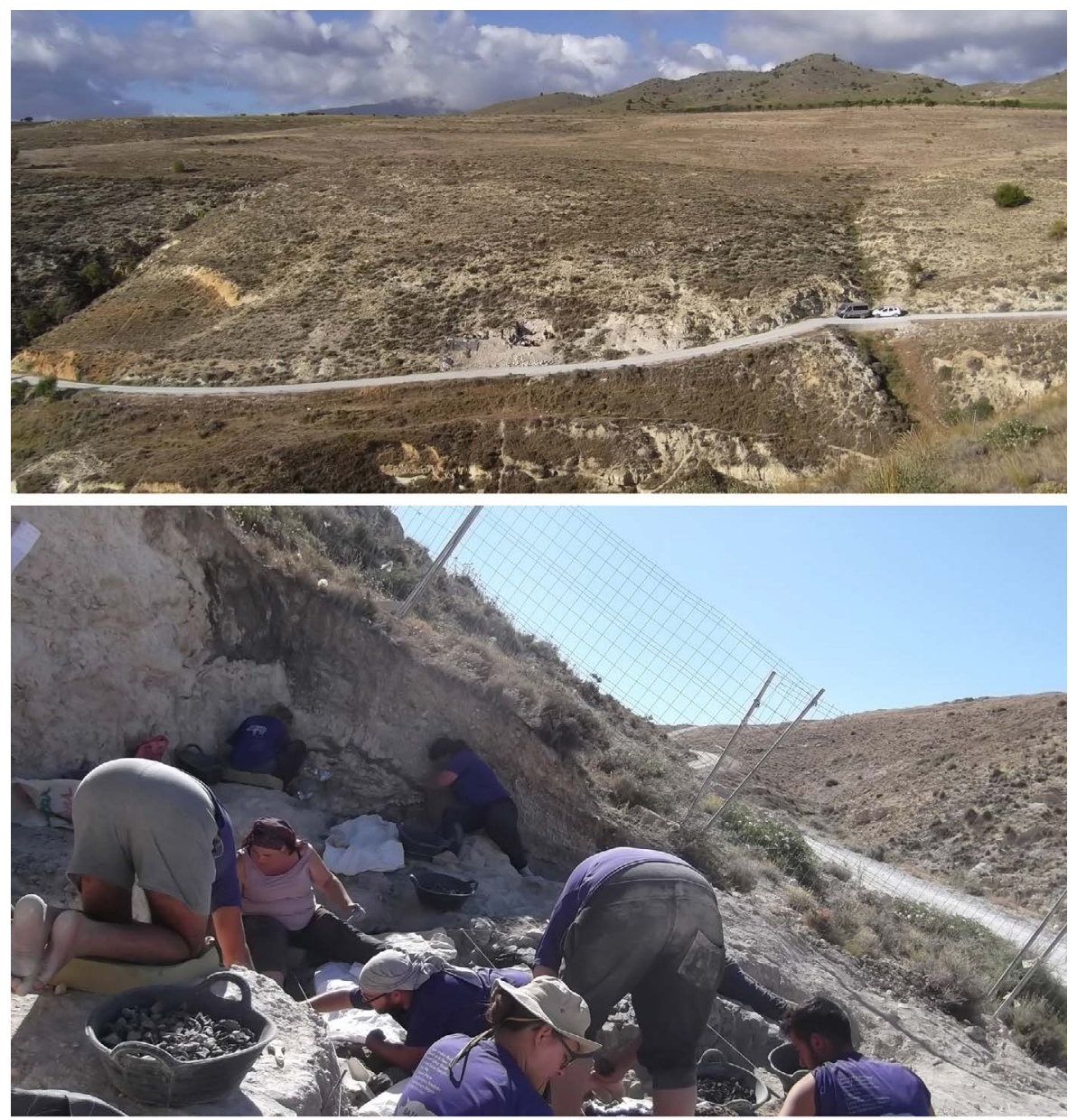

Yacimiento pliocénico de Baza-1 (Granada) durante la excavación de 2016. Arriba, vista general; abajo, excavación | foto S. Ros-Montoya 
realizar una prospección del área que permitiese decidir dónde ubicar un pequeño sondeo de tres por tres metros, el cual se realizó durante los años 2000 y 2001. En mayo de 2015, junio de 2016 y septiembre de 2017 nuestro equipo de investigación ha abierto nuevamente la excavación, autorizada por la Consejería de Cultura, gracias a la financiación del Ayuntamiento de Baza, con un área de trabajo amplia en la que se incluyen las cuadrículas iniciadas en las actuaciones previas.

El contexto sedimentario de los depósitos en los que se encuadra esta localidad paleontológica corresponde a un ambiente de tipo pantanoso, formado por niveles arcillosos oscuros con restos de plantas carbonizados, que incluyen abundantes restos fósiles de vertebrados.

El registro paleontológico se compone de un rico material fósil, en general con buen estado de conservación y una densidad de restos óseos muy alta. La lista faunística incluye once especies de roedores (Ruscinomys sp., Apocricetus barrierei, Debruijnimys julii, Apodemus gorafensis, Castillomys gracilis, Occitanomys cf. brailloni, Paraethomys meini, Paraethomys aff. abaigari, Stephanomys cordii, Trilophomys cf. castroi y Eliomys aff. intermedius), dos proboscídeos (=animales con trompa) (Anancus arvernensis y Mamut borsoni), dos bóvidos (uno de gran talla, Alephis sp., y otro de talla media, muy semejante a un antílope, que se encuentra en fase de estudio), un ciervo de talla media (Cervinae indet.), un rinoceronte (Stephanorhinus sp. cf. S. jeanvireti) y un pequeño caballo primitivo con tres dedos (Hipparion sp.) (ROS-MONTOYA; MARTÍNEZ-NAVARRO; ESPIGARES et ál., 2017; PIÑERO; AGUSTÍ; OMS et ál., 2017). El registro se completa con bastantes fragmentos de placas de tortuga, uno de ellos de gran tamaño, y hay que destacar que hasta el momento no se han encontrado restos de carnívoros.

Estos datos preliminares permiten concluir que la localidad de Baza-1 es de gran importancia, pues cronológicamente es algo más antigua de cuatro millones de años (Rusciniense), intervalo temporal que cuenta, como ya se ha indicado, con un exiguo registro de grandes mamíferos en el continente europeo. Otro dato muy interesante es la coexistencia de dos especies de mastodontes (Anancus arvernensis y Mamut borsoni), ya que escasean los yacimientos en los que aparecen asociados estos dos grandes megaherbívoros, siendo éste el primer y único yacimiento en la Península Ibérica donde ambos se encuentran juntos en el mismo nivel estratigráfico. Tales datos indican que el yacimiento de Baza-1 alberga una diversidad específica muy elevada, pues si bien el techo del tamaño corporal de los ungulados está probablemente representado por los dos proboscídeos, en tamaños inferiores debería estar registrada, potencialmente, una enorme cantidad de especies, básicamente rumiantes, y también diversos carnívoros. Se ha excavado todavía muy poco, pero el nivel fosilífero continúa y es muy probable que existan varios cientos de metros cuadrados, si no miles, con pre- 
sencia de restos fósiles, los cuales permitirán conocer, con el desarrollo de las excavaciones, mucho mejor el Plioceno inferior de la cuenca de Baza y de Europa en general.

La parte final del Rusciniense, próxima a la transición con el Villafranquiense, está muy bien representada en el yacimiento del Camp dels Ninots en Caldes de Malavella, en la provincia de Gerona (CAMPENY-VALL.LLOSERA; GÓMEZ DE SOLER, 2010; GÓMEZ DE SOLER; CAMPENY VALL-LLOSERA; MADE et ál., 2012), cuya edad se ha estimado en 3,2 millones de años.

Los fósiles del Camp dels Ninots se conservan en los depósitos de un maar, un lago fósil formado en un cráter volcánico. La lista faunística se compone de micro y macrovertebrados, entre los que abundan los peces del grupo de los ciprínidos (Leuciscus sp., Luciobarbus sp.), anfibios como salamandras (Pleurodeles sp.), tritones palmados (Lissotriton aff. helveticus) y ranas verdes (cf. Pelophylax perezi), tortugas representadas por las especies Mauremys leprosa y Chelydropsis cf. pontica, roedores como el ratón Apodemus atavus, además de grandes mamíferos como tapires (Tapirus arvernensis), bóvidos de gran tamaño (Alephis tigneresi) y rinocerontes (Stephanorhinus jeanvireti). Lo más importante es el estado de conservación de esta fauna, donde dominan los esqueletos completos, ya que los animales posiblemente murieron intoxicados a causa de la inhalación de gases volcánicos, quedando enterrados en el lago in situ de manera muy rápida. Por ello, poder estudiar esqueletos completos es un lujo en paleontología de vertebrados, lo que se da en muy pocas ocasiones. Esto convierte al yacimiento en un registro excepcional que permitirá realizar estudios paleobiológicos únicos sobre las especies allí fosilizadas.

\section{EL PLIOCENO SUPERIOR}

El tránsito del Plioceno inferior al superior se caracteriza por la llegada a Europa de las llamadas faunas villafranquienses (ROOK; MARTíNEZ-NAVARRO, 2010). El Villafranquiense, definido por PERETO (1865) es una edad mastológica que abarca un amplio periodo temporal, desde hace aproximadamente 3,4-3,2 millones de años hasta hace aproximadamente 1,1-1,2 millones de años, y se divide en inferior (hasta hace 2,6 millones de años, en el tránsito Plio-Pleistoceno), medio (hasta hace 2,0 millones de años, en la base del subcron paleomagnético normal Olduvai), y superior (hasta hace 1,1-1,2 millones de años, justo debajo del subcrón paleomagnético normal Jaramillo).

El Plioceno superior, correspondiente al llamado Villafranquiense inferior, el cual comprende cronologías entre 3,4-3,2 y 2,6 millones años, se caracteriza por retener todavía algunos taxones precedentes de afinidades subtropicales, típicos del Rusciniense. Incluye varias especies de habitantes

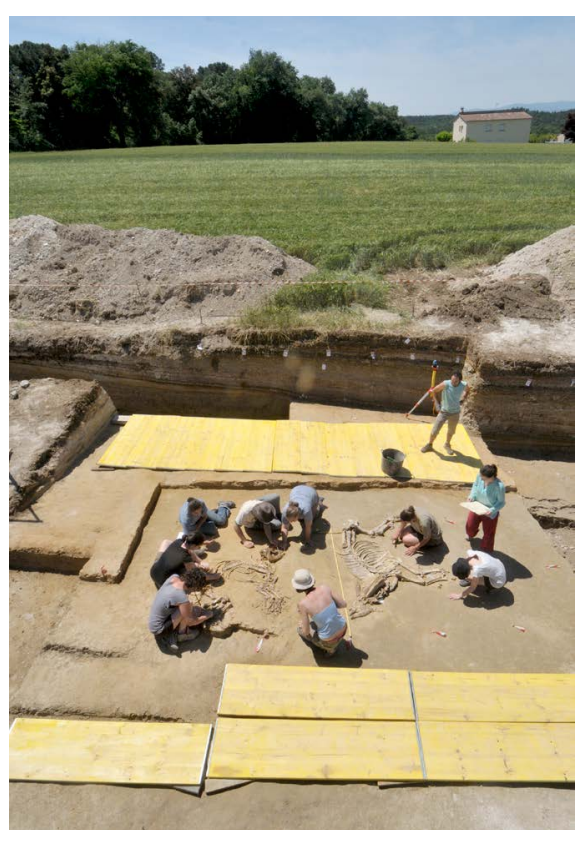

Yacimiento pliocénico del Camp dels Ninots (Caldes de Malavella, Gerona) | foto G. Campeny Vall.Ilosera 
de bosques húmedos, como el tapir Tapirus arvernensis, los mastodontes Mammut borsoni y Anancus arvernensis, el cerdo Sus minor, o el cercopitécido Mesopithechus monspessulanus. Estas especies se asocian a otras de nueva aparición en el continente, también relacionadas con ambientes boscosos, como el bovino Leptobos stenometopon, ya un auténtico búfalo, el rinoceronte Stephanorhinus elatus, el ciervo modelo gamo Pseudodama lyra, así como carnívoros tales como las hienas Pliocrocuta perrieri, de hábitos carroñeros, y Chasmaporthetes lunensis, de hábitos corredores y más cazadores, los tigres de dientes de sable Homotherium crenatidens y Megantereon cultridens, o el guepardo gigante Acinonyx pardinensis (ROOK; MARTíNEZNAVARRO, 2010).

A nivel europeo, un yacimiento típico de la base del Villafranquiense inferior es el de Vialette en el Macizo Central francés, datado en 3,14 millones de años (LACOMBAT; ABBAZZI; FERRETTI et ál., 2008).

En España, el Villafranquiense inferior está bien representado en diversos yacimientos distribuidos por gran parte del territorio, entre los cuales mere-

Yacimiento pliocénico del Canal de San Clemente (Huéscar, Granada). Arriba, vista general; abajo, defensa del mastodonte Anancus arvernensis | foto S. Ros-Montoya

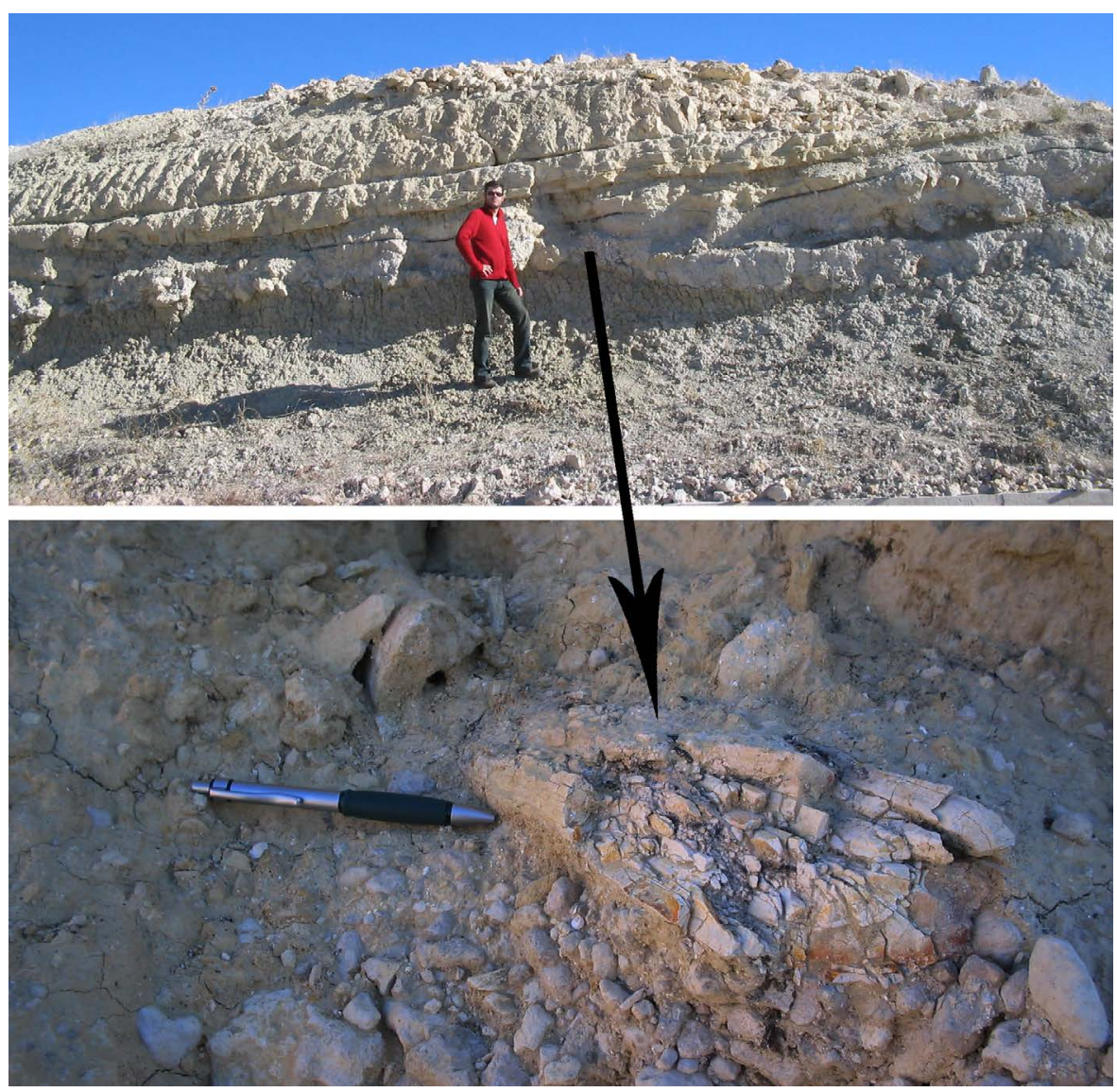


cen especial referencia el de Villarroya en la Rioja (ALBERDI; AZANZA; CERVANTES, 2016) y Las Higueruelas en Ciudad Real (MAZO; MADE; ARRIBAS et ál., 2003; SEQUEIROS, 2011). En una cronología similar estaría el yacimiento de Can Magrana, en Medinyà (provincia de Gerona), donde se registra la presencia de un molar de Mammut borsoni además de una fauna que incluye, entre otros, la presencia de Tapirus arvernensis (VILLALTA; LLOMPART, 1981). En la cuenca de Guadix-Baza son relevantes los yacimientos de Huéscar-3 (MAZO, 1989) y del Canal de San Clemente, también en Huéscar (MARTÍNEZ-NAVARRO; TORO; ROS-MONTOYA et ál., 2006), con presencia, además, de un gran número de niveles a lo largo de la cuenca con registros de microvertebrados.

Es de destacar en estas cronologías del Plioceno terminal la presencia de un yacimiento kárstico en brecha, situado en Moreda, junto a las estribaciones de la cuenca de Guadix-Baza, en su sector más meridional, en el que se registra un primate, un mono cercopitécido grande con un rostro similar al de los macacos y un cuerpo parecido al de un babuino, indicativo de hábitos más terrestres, llamado Paradolichopithecus, que se perpetúa en Europa y Asia hasta hace unos dos millones de años (MARIGÓ; SUSANNA; MINWER-BARAKAT et ál., 2014).

\section{EL PLEISTOCENO INFERIOR}

El límite Plio-Pleistoceno está marcado por el cambio paleomagnético de normal a negativo, el llamado límite Gauss/Matuyama, situado hace 2,59 millones de años.

La transición del Plioceno al Pleistoceno viene precedida por una importante crisis climática, una glaciación que marcará la tendencia hacia las condiciones de enfriamiento que se irán acentuando a lo largo de todo el Cuaternario durante los sucesivos ciclos climáticos.

Durante esta transición se perpetúan algunas especies presentes en el Plioceno terminal como el mastodonte Anancus arvernensis, el guepardo Acynonix pardinensis, las hienas Pliocrocuta perrieri y Chasmaporthetes lunensis, o los tigres de dientes de sable Homotherium crenatidens y Megantereon cultridens, entre otros. Pero, además, se produce un importante recambio faunístico en Europa, marcada por la llegada de dos importantes taxones, el elefante moderno correspondiente al género Mammuthus y el caballo monodáctilo que sustituye a los hipariones, con tres dedos, correspondiente al género Equus. Este evento es conocido como el "Elephant/Equus event" (LINDSAY; OPDYKE; JOHNSON, 1980; AZZAROLI, 1983, 1995). A estos inmigrantes hay que sumar la llegada de los ciervos gigantes del género Eucladoceros, antílopes como Gazella borbónica, muy esbelta, o Gazellospira torticornis 
que, como su nombre indica, presenta los cuernos de crecimiento espiralado, caprinos como Gallogoral meneghini, o cerdos como Sus strozzi, parecido al actual jabalí verrugoso de Java (Sus verrucosus) en el sureste asiático.

En España, el Villafranquiense medio está bien representado en varios yacimientos, pero destaca especialmente en la localidad de La Puebla de Valverde en Teruel, muy rica en grandes mamíferos como carnívoros (KURTEN; CRUSAFONT-PAIRÓ, 1977) y ungulados, donde aparece también el mono cercopitécido Paradolichopithecus arvernensis. Está datada en una cronología comprendida entre 2,0 y 2,1 millones de años (SINUSIA; PUEYO; AZANZA et ál., 2004). El mono $P$. arvernensis también está representado en el yacimiento de Cova Bonica, Vallirana, en el macizo del Garraf, junto a Barcelona (MARIGÓ; SUSANNA; MINWER-BARAKAT et ál., 2014).

Por lo que se refiere a la cuenca de Guadix-Baza, donde existe el mejor registro de toda la Península Ibérica para el Plio-Pleistoceno, el Villafranquiense medio está muy bien representado en algunos afloramientos en la región próxima al embalse del Negratín (AGUSTí; OMS; REMACHA, 2001), en la cubeta de Guadix, en el yacimiento de Huélago (ALONSO DIÁGO; HOYOS GÓMEZ; ALBERDI, 2002) y en la cubeta de Baza, cuya localidad más significativa de este periodo es, sin duda, el yacimiento de Fuente Nueva-1, situado en la base de la Cañada de Vélez de Orce, próximo al Cortijo de la Mojona, a unos dos kilómetros al este de la pedanía de Fuente Nueva, en el talud del camino que la une con Orce.

Fuente Nueva-1 se localizó durante las primeras prospecciones desarrolladas en los años ochenta por el equipo dirigido por Josep Gibert y la primera publicación sobre el yacimiento se realizó en 1987 por parte de Salvador Moyà-Solà y sus colaboradores (MOYÀ-SOLÀ; AGUSTí; MARÍN, 1987).

Este yacimiento está enclavado en unos niveles con calizas y margas, entre las que se encuentra un nivel de sílex nativo, calcedonia, de entre 15 y 25 $\mathrm{cm}$ de espesor, con una extraordinaria abundancia de restos óseos tanto por encima como por debajo del nivel silíceo. Para hacerse una idea de la densidad de fósiles, baste indicar que en la campaña de 2015, en solo cuatro metros cuadrados, se exhumaron 253 restos óseos, correspondientes a diez especies diferentes de grandes vertebrados, entre ellos abundantes núcleos óseos (cuernos) de gacela, correspondientes a la especie Gazella borbónica, conjuntamente con otro núcleo óseo de un antílope con cuernos torsionados (espiralados), llamado Gazellospira torticornis. Además, se recuperó una mandíbula de caballo de gran talla, perteneciente a la especie Equus stenonis, restos de caprinos y otros bóvidos de gran tamaño, ciervos, un fragmento de diente de leche de elefante, un premolar deciduo (de leche) correspondiente a un individuo infantil de hiena, adscrito a la especie Pliocrocuta perrieri, cuyo tamaño y anatomía eran parecidos a los de la hiena 


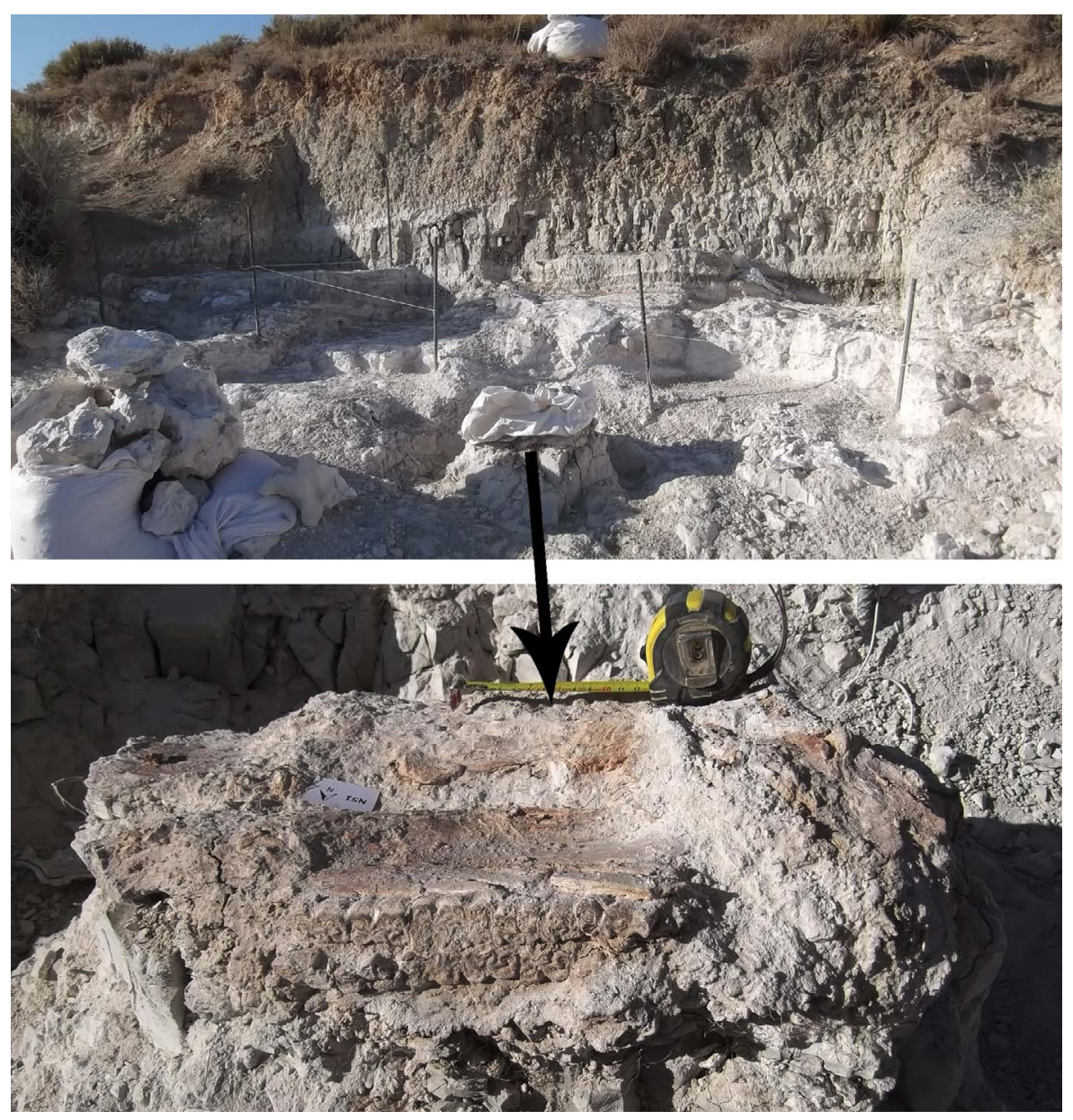

parda sudafricana actual (Parahyaena brunnea), además de varios fragmentos de placas correspondientes a caparazones de tortuga (ROS-MONTOYA; MARTÍNEZ-NAVARRO; ESPIGARES et ál., 2016).

Desgraciadamente, las escasas excavaciones realizadas, aunque sumamente productivas en fósiles, no han permitido determinar todavía el potencial de esta localidad paleontológica, pues su extensión, en estrato horizontal, debe de ser de bastantes miles de metros cuadrados, a buen seguro plagados de fósiles, con una diversidad faunística mucho más amplia de lo que se conoce hasta el momento.

\section{EL VILLAFRANQUIENSE SUPERIOR}

Sin duda, el mejor registro del Villafranquiense superior de España, de todo Europa y, uno de los mejores de todo el mundo, es el de la cuenca de Guadix-
Yacimiento del Pleistoceno inferior (Villafranquiense medio) de Fuente Nueva 1 (Orce, Granada). Arriba, excavación; abajo, detalle de una mandíbula del caballo Equus stenonis | foto S. Ros-Montoya 
Baza, y especialmente el del sector de Orce y sus dos pedanías, Fuente Nueva y Venta Micena, conocido como el Olduvai español, en referencia al legendario yacimiento paleoantropológico tanzano de fama mundial.

La transición del Villafranquiense medio al superior (entre 2,0 y 1,8 millones de años) se conoce gracias a diversos yacimientos, entre ellos cabe nombrar el de Fonelas P-1 (ARRIBAS; GARRIDO; VISERAS et ál., 2009), próximo a la ciudad de Guadix, pero conviene indicar que esta transición se encuentra igualmente bien registrada en Orce, en las localidades de Barranco de los Conejos, Cortijo de D. Diego o Cortijo Alfonso (AGUSTí; BLAIN; FURIÓ et ál., 2013).

El comienzo del Villafranquiense superior se caracteriza por un nuevo recambio faunístico, muy importante, pues pocas especies que habitaban el continente con anterioridad sobreviven a las nuevas condiciones climáticas y ecológicas, aunque algunas muy significativas sí lo hacen, como el elefante meridional, Mammuthus meridionalis. Estos proboscídeos, de origen africano, se adaptan a los climas de mayor contraste estacional de las latitudes medias de Europa y Asia, comportándose como herbívoros generalistas, capaces de consumir todo tipo de vegetales, tanto hojas a distintas alturas de las ramas de los árboles como sobre todo hierbas en las praderas. La evolución de este gigante viene marcada por la adquisición de unos molares con la corona progresivamente más alta que, además, incrementan paulatinamente el número de láminas de esmalte, las cuales se hacen progresivamente más finas y se empaquetan más, adquiriendo con el tiempo mayor resistencia a la abrasión. Este cambio en la forma de los dientes permite a los proboscídeos consumir alimentos más abrasivos y, a la vez, menos nutritivos, lo que les faculta a sobrevivir durante el proceso de estepización (propio de climas más secos y fríos) que se desarrolla en Europa a lo largo de todo el Cuaternario. Esta evolución es típica en el género Mammuthus y se acentúa hasta su grado más desarrollado en las formas terminales del linaje, el llamado Mammuthus primigenius, el elefante del frío, el mamut lanudo típico del final del Pleistoceno.

El Villafranquiense superior viene marcado en general por la aparición de nuevas especies, fundamentalmente ungulados procedentes de Asia, en especial rumiantes (cérvidos, bóvidos y jiráfidos), además de équidos y algunas otras, escasas pero muy significativas, procedentes de África, entre las que destaca, por supuesto, la llegada del género Homo, cuyas evidencias más antiguas se han registrado en Georgia, en el Cáucaso, a las puertas de Europa, en el mundialmente conocido yacimiento de Dmanisi, datado en 1,8 millones de años y donde se han encontrado hasta el momento cinco cráneos humanos muy completos, que oscilan en capacidad cerebral entre 550 y $750 \mathrm{~cm}^{3}$, valores similares a los de los Homo habilis africanos, cuatro mandíbulas, vértebras, costillas y huesos de las extremidades, acompaña- 
dos de una amplia colección de industrias líticas y otras evidencias de actuación humana sobre los cadáveres de grandes mamíferos. Sin embargo, los homininos llegan a Europa occidental algo más tarde, como se explica más adelante, por lo que en nuestra península, y en general en Europa, esta transición del Villafranquiense medio al superior está marcada por lo que Azzaroli (1983) Ilamó "the Wolf event" (el evento del lobo), caracterizado por el enorme impacto que produce en este momento la llegada de los cánidos de aspecto moderno a los ecosistemas europeos, si bien el registro de los lobos modernos ya se había producido en Europa unos cientos de miles de años antes.

Modestamente, Martínez-Navarro (2010) propuso que este evento debería llamarse realmente "the Pachycrocuta brevirostris event" (el evento Pachycrocuta brevirostris), pues el impacto que produce la llegada de esta hiena gigante, procedente de África, en las asociaciones faunísticas acumuladas en lo que resta del Pleistoceno inferior, hasta hace 0,8-0,9 millones de años, es mucho más importante que el de los cánidos, ya que este supercarroñero está presente en prácticamente todas partes y, además, es el causante de la mayoría de las acumulaciones de restos óseos en Eurasia, desde la Península Ibérica hasta China e Indonesia. Pachycrocuta brevirostris era una hiena gigante caricorta, cuya masa corporal, calculada en función de las dimensiones de sus dientes y huesos, sobrepasaría los $110 \mathrm{~kg}$ (PALMQVIST; MARTÍNEZ-NAVARRO; PÉREZ-CLAROS et ál., 2011); tales dimensiones asombran al compararlas con las de las hienas actuales, pues las duplican, pero algunos ejemplares de la especie podrían llegar a pesar más de $150 \mathrm{~kg}$, un peso medio entre el de un león y una leona actuales. La ecología y el comportamiento de esta hiena ha sido especialmente estudiada por nuestro equipo en el yacimiento de Venta Micena en Orce.

Pachycrocuta brevirostris presenta un cráneo muy robusto, con una dentición a nivel de los premolares y una musculatura facial muy sólidas y resistentes, al igual que sus miembros, proporcionalmente cortos y muy fornidos, mucho más que en cualquiera de las hienas actuales. Se trata, pues, de un carroñero sistemático, capaz de abrir, descuartizar y comerse cualquier cadáver que encuentre, aprovechándolo todo, desde los tejidos blandos hasta fracturar los huesos más resistentes, con el objetivo de extraer el tuétano o el cerebro en el caso de los cráneos y, por ello, es el gran competidor con los homininos por el aprovechamiento de la carroña. Debemos entender que el llamado Villafranquiense superior (entre 2,0 y 1,2 millones de años) y el Epivillafranquiense (entre 1,2 y 0,8 millones de años, aproximadamente) se caracterizan en Eurasia por ser un escenario en el que humanos y hienas competían por el bien más preciado, los cadáveres de los animales cazados por otros depredadores o muertos por causas naturales. Nuestros antepasados y estas hienas eran dos supercarroñeros que presumiblemente se conocían bien, se observaban, luchaban y, en la mayoría de las ocasiones, eran 

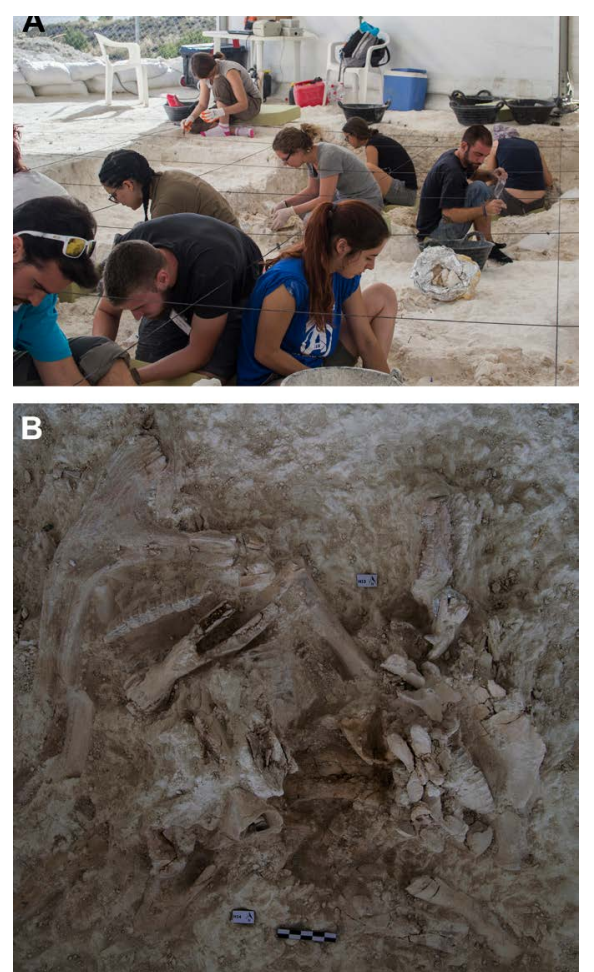

Excavación del corte 4 en el yacimiento del Pleistoceno inferior de Venta Micena (Orce, Granada). Arriba, excavación; abajo, detalle de una acumulación de restos | foto S. Ros-Montoya estas últimas las vencedoras, pues su registro en el continente, tanto a nivel de fósiles de la especie como de acumulaciones de restos óseos generadas por ellas, es mucho más abundante que el de los homininos.

El escenario ecológico mejor conocido del Villafranquiense superior en todo el continente europeo es el del yacimiento de Venta Micena, localidad paleontológica única y paradigmática para las ciencias que se ocupan del estudio del pasado. Se trata de un estrato horizontal de caliza micrítica, de 80 a 120 cm de espesor, que se puede seguir a lo largo del relieve durante más de 2,5 kilómetros y se ha calculado, proyectando su extensión areal, que tiene más de un kilómetro cuadrado de sedimentos repletos de fósiles, es decir, más de un millón de metros cuadrados con restos óseos, de los que sólo se han excavado por el momento unos 350 metros cuadrados, los cuales presentan una densidad superior a 50 fósiles por metro cuadrado. Por ello, Venta Micena es el yacimiento más rico en restos faunísticos del Cuaternario de toda Europa y uno de los más ricos de todo el mundo, rivalizando con localidades como Rancho La Brea en el Pleistoceno superior de California.

El Villafranquiense superior se caracteriza por la llegada al continente europeo de nuevas especies, como un caballo de anatomía parecida a la moderna cebra de Grevy, llamado Equus altidens, procedente de Asia, que sustituye a las formas anteriores representadas en Fuente Nueva-1, correspondientes a la especie Equus stenonis.

Entre los perisodáctilos, animales ungulados con dedos impares, además de los caballos, que sólo conservan un dedo (una pezuña), se localizan también los rinocerontes, que presentan tres dedos. El Villafranquiense superior se caracteriza por la llegada de una nueva especie, Ilamada Stephanorhinus hundsheimensis, que toma su nombre del yacimiento centroeuropeo de Hundsheim y se distingue por tener el cráneo proporcionalmente más ancho (braquicéfalo) que su antecesora, llamada Stephanorhinus etruscus. Este rinoceronte, ramoneador de hojas en el límite entre las zonas arboladas y arbustivas con los espacios abiertos, tenía hábitos similares al rinoceronte negro africano actual (Diceros bicornis) y se perpetúa en Europa durante el Epivillafranquiense hasta ya entrado el Pleistoceno medio, hace aproximadamente 0,7 millones de años.

Pero éstas no son las únicas novedades. Es especialmente remarcable la llegada de nuevas especies de rumiantes, entre las que conviene citar la aparición, durante la transición Villafranquiense medio-superior, de una jirafa correspondiente al género Mitilanotherium, localizada por el momento solo en la cuenca de Guadix, en dos yacimientos, Huélago y Fonelas P-1, pero que aún no se ha registrado en la región de Orce, aunque es probable que aparezca en futuras campañas de excavación. También se incorporan al registro nuevas especies de bóvidos y cérvidos, que sustituyen a las prece- 
dentes. En Venta Micena se localizan dos especies de ciervo, una de gran tamaño, llamada Praemegaceros verticornis, de unos $400 \mathrm{~kg}$ de masa corporal, cuyos machos exhiben unas cuernas de casi 1,5 metros, compuestas por una rama principal y diversos candiles (puntas). Por su dentición braquidonta (muelas de corona baja) sabemos que estaba adaptada a consumir hojas y brotes tiernos de árboles y arbustos, por lo que habitaba en ambientes boscosos relativamente abiertos o en el tránsito entre las praderas y los bosques, pues dada su cornamenta, en las épocas de máximo desarrollo de las cuernas los machos no podrían desenvolverse por espacios boscosos cerrados. También hay una segunda especie de ciervo, en este caso de tamaño mediano, equivalente al de un gamo, llamada Metacervocerus rhenanus, adaptada a consumir pastos más secos y aprovechar eficientemente el contenido hídrico de la vegetación. Además, aunque todavía no se ha caracterizado bien en Venta Micena, es muy probable que en un futuro se identifique otro ciervo de tamaño pequeño, el correspondiente a un corzo.

Sin embargo, los bóvidos son los rumiantes más diversos, abundantes y significativos en estas cronologías. El Villafranquiense superior se caracteriza por la llegada de los primeros bisontes a Europa, que son los típicos habitantes de las praderas y bosques abiertos, los cuales se localizan por primera vez en Dmanisi. Los bisontes evolucionan directamente desde formas primitivas correspondientes al género Leptobos, que se perpetúan hasta el tránsito Villafranquiense medio-superior y cuyos últimos representantes se encuentran en la cuenca de Guadix-Baza en el yacimiento de Fonelas P-1. Después los bisontes, ya de aspecto moderno, son característicos en el resto del Pleistoceno, perviviendo hasta la actualidad en Europa con la especie Bison bonasus. Los bisontes son muy abundantes en Venta Micena y en los demás yacimientos de Orce, así como en otras localidades paleontológicas de edades similares, como Incarcal en Crespià (Gerona) (ROSMONTOYA; MADURELL-MALAPEIRA; MARTÍNEZ-NAVARRO et ál., 2012). Además, en Venta Micena se localiza otra especie de búfalo, el llamado Hemibos aff. gracilis, descrita en el yacimiento chino de Longdan en el año 2004. Se trata de una forma muy extraña, no localizada con anterioridad, que se ha descrito muy recientemente en Europa. Esta especie, de origen asiático, ha sido citada por primera vez en Orce y en nuestro continente (MARTÍNEZ-NAVARRO; ROS-MONTOYA; ESPIGARES et ál., 2011). Se trata una forma adaptada a ambientes boscosos y corresponde a un ancestro de los búfalos de agua, de cuyas hembras se extrae la leche con la que se fabrica la mozzarella.

El conjunto de especies de bóvidos se caracteriza, además, por la llegada de los ancestros de los bueyes almizcleros, localizados por primera vez en el yacimiento del Barranco de los Conejos, cuya cronología se ha estimado en 1,8 millones de años, donde se encuentra un núcleo óseo (un cuerno) correspondiente a este linaje, llamado Praeovibos (anterior a Ovibos moschatus, el 
actual buey almizclero). En la actualidad, esta especie está totalmente adaptada a la vida en las latitudes boreales y gélidas del círculo polar ártico, pero en el Pleistoceno inferior vivían en ambientes mediterráneos más benignos, como las estribaciones montañosas de la cuenca de Guadix-Baza, aunque los estudios isotópicos sugieren que los líquenes formaban ya parte de su alimentación. Es muy común también la presencia de otro bóvido, pariente próximo de los bueyes almizcleros, llamado Soergelia minor (MOYÀ-SOLÀ, 1987). Se trata de un animal muy extraño, con la base de los cuernos dirigidos lateralmente y hacia delante. Es un animal muy característico, que se localiza en Europa entre 1,8 y 1,5 millones de años, asociado a la primera dispersión del género Homo hacia nuestro continente. Como tal, está presente en Dmanisi, en Venta Micena y, también en la Península Ibérica, se ha hallado recientemente en el yacimiento del Alto de las Picarazas, en la provincia de Valencia, asociado a industria lítica (VICENTE GABARDA; MARTÍNEZ VALLE; GUILLEM CALATAYUD et ál., 2016). Los estudios ecomorfológicos han permitido poner de manifiesto que su alimentación era mixta sobre hojas y hierba, presentando dientes con una altura de corona intermedia.

Finalmente, se ha localizado también una cabra pacedora de hierba, Capra alba (MOYÀ-SOLÀ, 1987), cuyo nombre está dedicado al color blanco de la caliza micrítica del yacimiento de Venta Micena. Al igual que en el caso de Soergelia, los análisis biogeoquímicos permiten constatar que había desarrollado ya las adaptaciones fisiológicas que facultan a los caprinos modernos el subsistir con el agua de la vegetación que ingieren.

Sin embargo, el ungulado más característico del Villafranquiense superior y del Epivillafranquiense es, sin lugar a dudas, el artiodáctilo gigante de cuatro dedos, el hipopótamo de origen africano llamado Hippopotamus antiquus, que es una especie hermana, si no la misma, que Hippopotamus gorgops, bien conocido durante el Pleistoceno inferior en África oriental y en el Corredor Levantino, en Israel y Palestina. Esta especie se dispersa desde África en el Villafranquiense superior, aunque hay algunas citas discutidas sobre su presencia en el Villafranquiense medio italiano, en un yacimiento llamado Coste San Giacomo. Se convierte en un taxón abundante en las asociaciones faunísticas de Europa a partir del momento faunístico Venta Micena, hace aproximadamente 1,6 millones de años, y se perpetúa hasta hace unos 0,6 millones de años. Se trata de una especie muy particular y especialmente relevante para explicar el entorno ecológico y climático de los primeros homininos de nuestro continente, pues los análisis ecomorfológicos e isotópicos han mostrado que tenía una dependencia más estricta por el medio acuático que la especie actual, alimentándose solo de vegetación acuática en lugar de salir del agua por la noche a pacer hierba.

Entre los carnívoros, el registro es muy abundante tanto en Venta Micena como en los otros dos yacimientos de Orce ampliamente excavados, 
Barranco León y Fuente Nueva-3. Así, se encuentran fósiles abundantes, además de rastros de su actividad, de la hiena gigante de cara corta, procedente de África, Pachycrocuta brevirostris, como ya se ha indicado, pero además hay una buena representación de tigres de dientes de sable, uno grande del tamaño de un león, Homotherium latidens, y otro más pequeño, Megantereon whitei, con dimensiones similares a las de un jaguar, del cual se explican sus características a continuación. También hay restos de jaguares, linces, zorros, chacales, licaones, osos y tejones.

Son de destacar los estudios sobre el tigre de dientes de sable de origen africano Megantereon whitei, cuyo registro más antiguo fuera de África se encuentra en el yacimiento de Dmanisi a 1,8 millones de años, junto con los primeros homininos de Eurasia. Esta especie era un félido super-depredador que cazaba por emboscada y se desenvolvía en hábitats mixtos (arbolados y abiertos). Poseía fuertes miembros anteriores, unos caninos superiores muy alargados, de unos $10 \mathrm{~cm}$ de altura en la corona y con bordes lisos, sin crenulaciones, comprimidos lateralmente como puñales, y una mandíbula corta de mentón pronunciado, con la dentición premolar reducida en tamaño. Estaba muy bien adaptado para cazar al acecho herbívoros ungulados de tamaño medio a grande, pero su estructura masticatoria sólo le permitía acceder a las partes más blandas de sus presas, especialmente las vísceras y paquetes musculares, por el peligro que suponía fracturarse los caninos, dada su longitud y fragilidad, a la hora de entrar en contacto con las partes duras. Por ello, su comportamiento habitual sería abrir el abdomen, comer las vísceras y dejar la mayor parte de los cadáveres intactos, siendo éstos posteriormente aprovechados por los carroñeros, especialmente por la hiena gigante Pachycrocuta brevirostris, pero probablemente también por nuestros antepasados, los primeros homininos de Europa (MARTÍNEZ-NAVARRO; PALMQVIST, 1995, 1996; PALMQVIST; TORREGROSA; PÉREZ-CLAROS et ál., 2007).

Estudios similares han sido llevados a cabo con el perro pintado del Pleistoceno inferior Lycaon lycaonoides, ancestro de los actuales licaones africanos (MARTÍNEZ-NAVARRO; ROOK, 2003). La investigación fundamental se basa en el hallazgo de un cráneo muy peculiar, conservado completo, procedente de Venta Micena (el espécimen siglado como VM 7000), localizado en la campaña del año 1995. Este fósil corresponde a un individuo viejo, de unos 6 ó 7 años, que muestra varias anomalías: es bilateralmente asimétrico y le faltan una serie de piezas dentales fundamentales. Así, tras un análisis radiológico fue posible demostrar que, durante su vida, nunca tuvo el canino superior derecho, que es una pieza clave y fundamental en cualquier depredador. Estas anomalías fueron consecuencia, probablemente, del alto grado de consanguineidad presente en las poblaciones de la especie en la cuenca de Guadix-Baza. En una especie hipercarnívora, como las del linaje de los perros pintados africanos modernos, este indi-
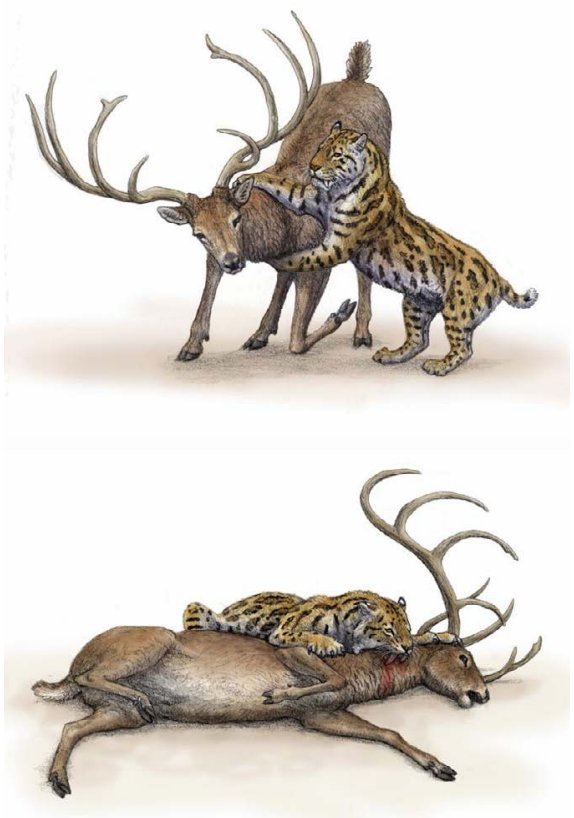

Tigre de dientes de sable, Megantereon whitei, cazando un ciervo gigante, Praemegaceros verticornis, interpretado en el registro de Venta Micena | ilustración Mauricio Antón 
viduo sobrevivió hasta llegar a una edad adulta pese a sus taras tan marcadas. La supervivencia de individuos patológicos tan longevos como éste sugiere que el comportamiento social colaborativo en el cuidado y la ayuda a individuos enfermos, discapacitados y/o viejos por parte de otros miembros de la familia, como ocurre en los licaones actuales Lycaon pictus, ya estaba desarrollado en el Pleistoceno inferior, hace por lo menos un millón y medio de años (PALMQVIST; ARRIBAS; MARTíNEZ-NAVARRO, 1999). Un comportamiento social similar, ayudando a un individuo humano viejo y desdentado, se ha detectado en el yacimiento de Dmanisi en el Cáucaso gracias al hallazgo del cráneo D3444 y la mandíbula D3900, que carecen de la práctica totalidad de los dientes, perdidos años antes de sobrevenirle la muerte al individuo, como indica el avanzado estado de reabsorción de tejido óseo alveolar, mostrando así una convergencia entre el comportamiento de

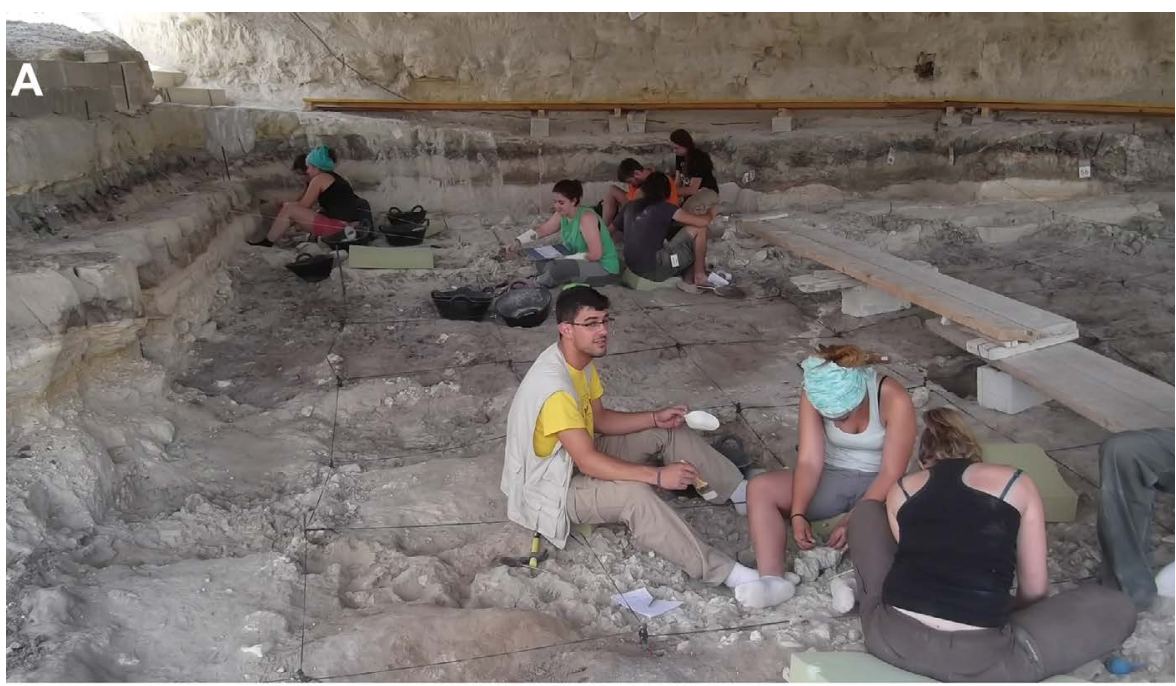

Yacimiento del Pleistoceno inferior (Villafranquiense superior) de Barranco León (Orce, Granada). Arriba excavación; abajo, detalle de una cuadrícula con industria lítica y restos óseos | foto S. Ros-Montoya

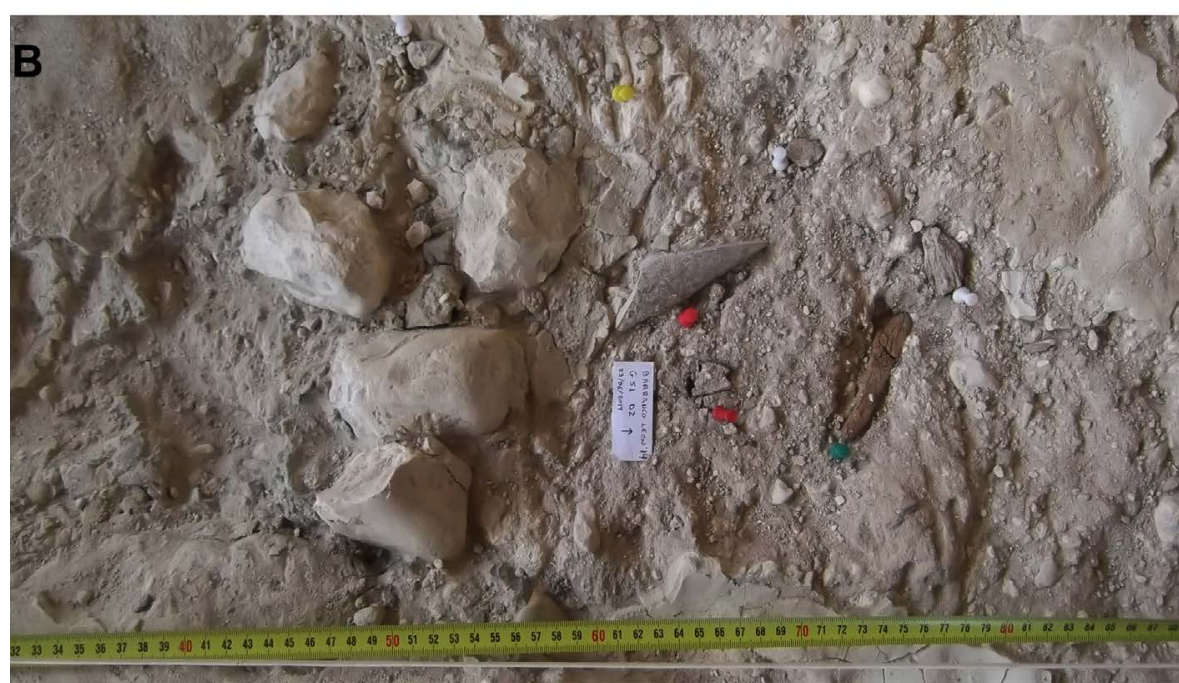




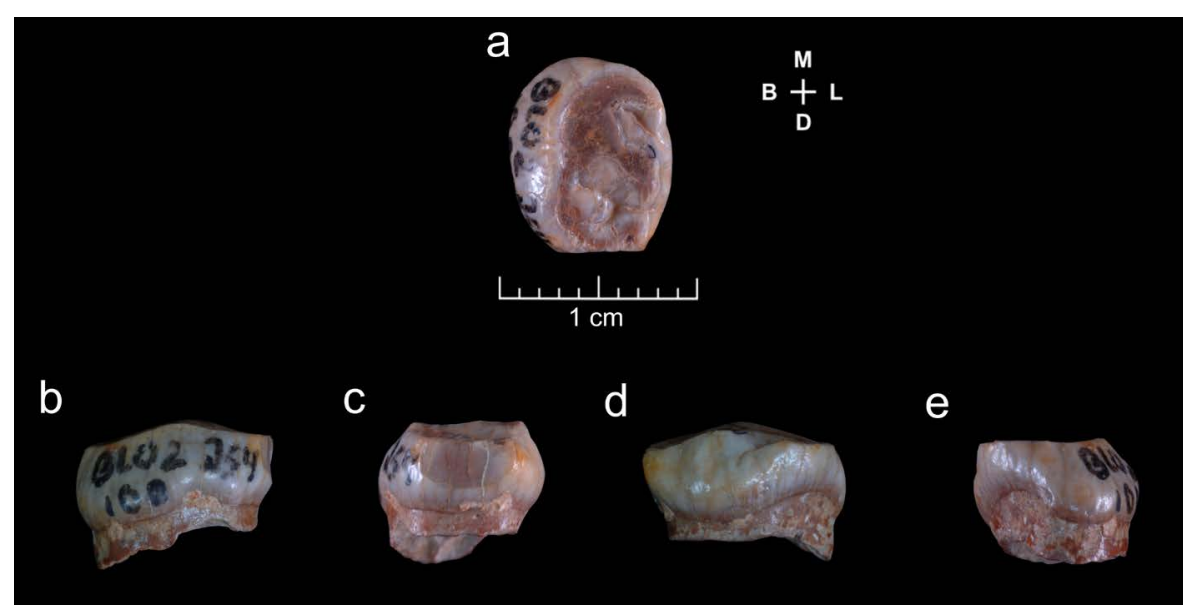

los grandes carnívoros sociales y el de los humanos primitivos con hábitos carnívoros manifiestos. Curiosamente, los perros pintados se dispersaron desde Eurasia hacia África al mismo tiempo (1,9-1,8 millones de años) que los homininos abandonaban África y siguiendo la misma ruta, el corredor levantino, pero en sentido opuesto.

El yacimiento de Barranco León, conocido desde los primeros años ochenta gracias a los trabajos de prospección del equipo que dirigía entonces $\mathrm{J}$. Gibert, está datado en 1,4 millones de años y ha dado una importante cantidad de restos faunísticos asociados a la industria lítica, pero ha pasado a la literatura científica principalmente por haber brindado el resto humano más antiguo exhumado en Europa hasta el momento. Se trata de un diente de leche correspondiente a un niño o niña de unos diez años de edad, que probablemente murió en Barranco León y pudo haber sido comido parcialmente por las hienas u otros carnívoros, quedando enterrado por partes. De momento sólo hemos encontrado esta pieza, pero es probable que en un futuro aparezcan nuevos fósiles humanos correspondientes a este individuo (TORO-MOYANO; MARTÍNEZ-NAVARRO; AGUSTÍ et ál., 2013).

El yacimiento de Fuente Nueva-3 es, hoy por hoy, probablemente el mayor espectáculo en el mejor teatro del Pleistoceno inferior de Europa. Esta localidad fue descubierta por dos niños, los hijos de Paula Ninou, que pasaban sus vacaciones en una casa cueva situada justo encima del afloramiento. Ellos se lo enseñaron a un vecino, gran aficionado a la arqueología, Alain Bocquet, quien se lo mostró a uno de nosotros (Bienvenido Martínez Navarro) el 5 de mayo de 1991. Fuente Nueva 3 es un verdadero cementerio de elefantes. Es probablemente aquí donde mejor se interpreta el comportamiento de nuestros primeros antepasados en el continente europeo para proveerse de alimentos de origen animal, en competencia directa con los grandes carnívoros, especialmente con las hienas gigantes caricortas. En algo más de 100

Diente fósil BL02-J54-100, primer molar de leche inferior izquierdo (dm1) del yacimiento de Barranco León D. a: vista oclusal; b: vista labial; c: vista distal; d: vista lingual; y e: vista mesial | fuente modificado a partir de TORO; MARTÍNEZ-NAVARRO; AGUSTÍ et ál., 2013 


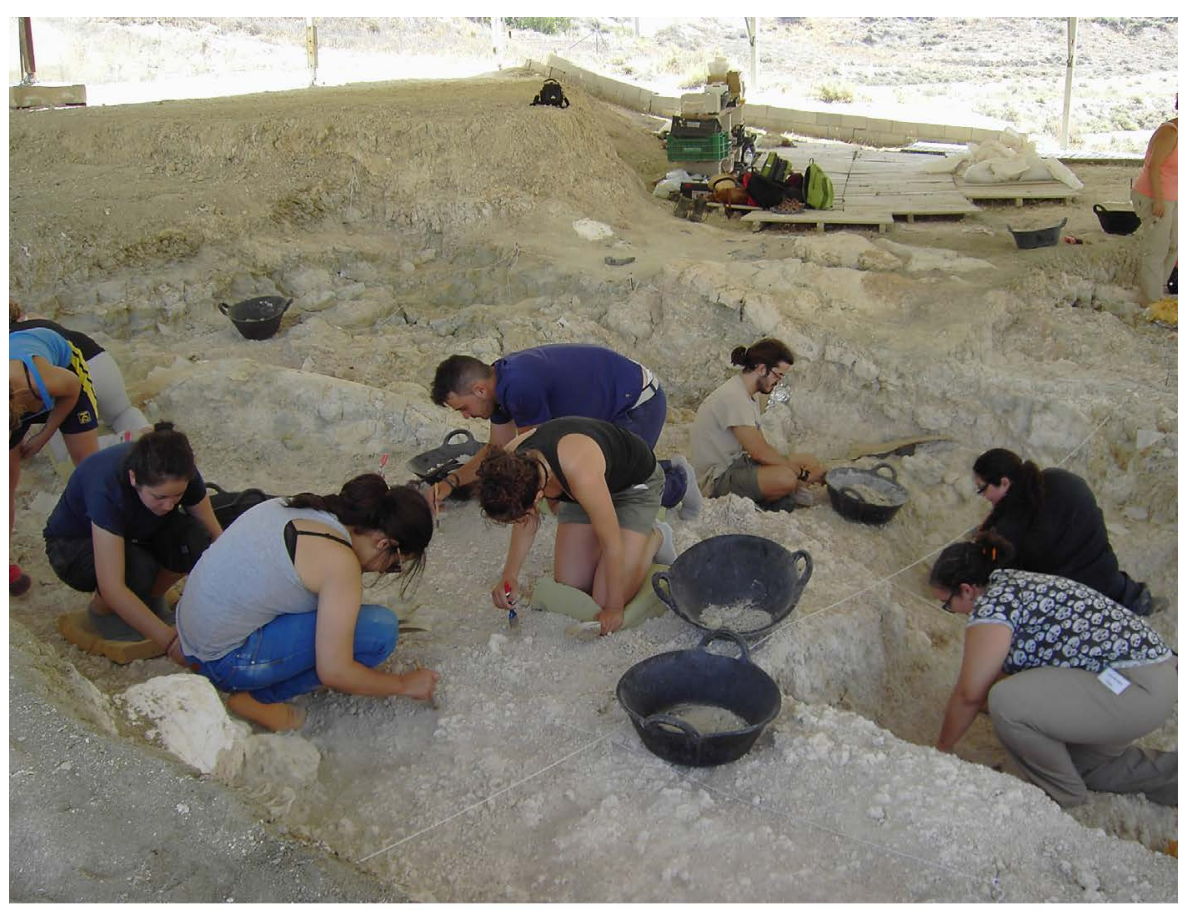

Yacimiento de Fuente Nueva-3, Villafranquiense superior (Orce, Granada). Arriba, excavación; debajo, detalle de las defensas de un individuo macho gigante de Mammuthus meridionalis | fotos S. Ros-Montoya

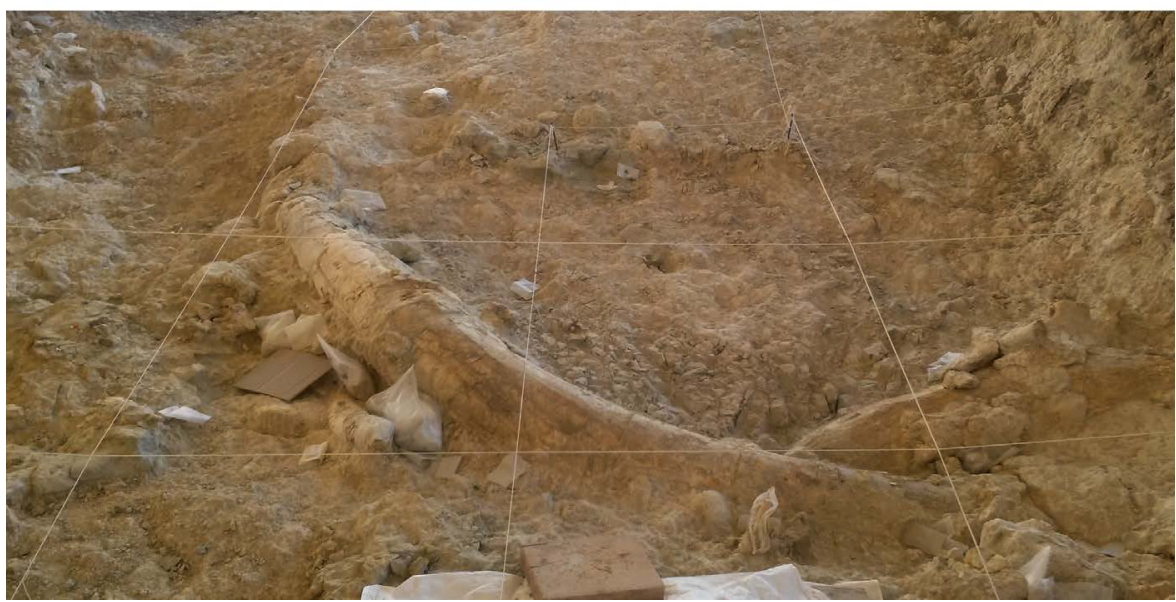

metros cuadrados se han localizado restos correspondientes a un mínimo de 10 individuos de elefantes de la especie Mammuthus meridionalis, que incluyen un macho gigante con unas defensas torsionadas de más de cuatro metros de largo y $32 \mathrm{~cm}$ de diámetro, lo que indica que debía tener una altura en vida de más de cinco metros y una masa de 12 a 15 toneladas. También se encuentran varias hembras y crías. Además, son abundantes los restos de otros megaherbívoros, como hipopótamos, rinocerontes, bisontes, ciervos gigantes y caballos, todos ellos comidos por homininos y carnívoros, en base a la enorme cantidad de industria lítica localizada y a la presencia de marcas de fractura y de corte en los huesos, así como a otras marcas producidas 


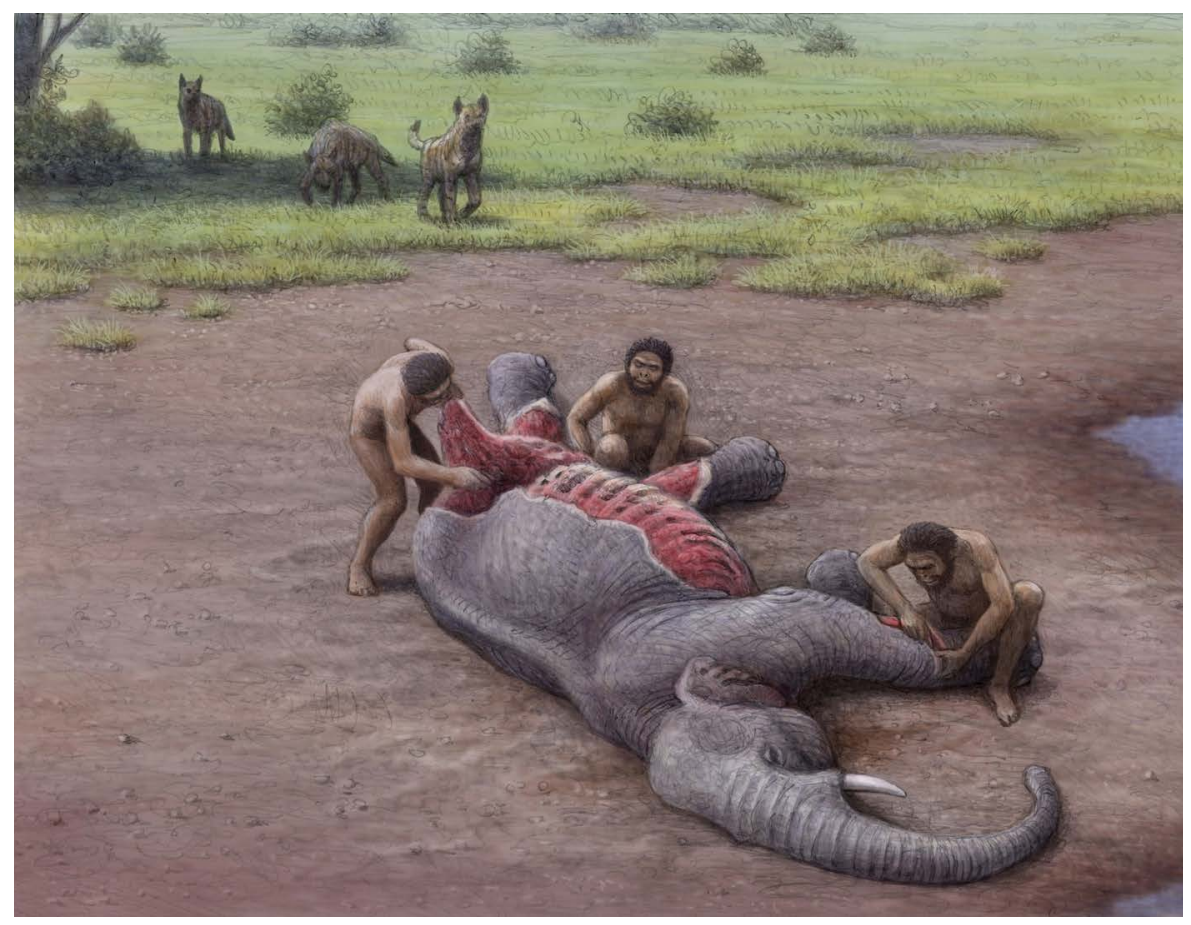

por los dientes de los carnívoros y la presencia de coprolitos (excrementos Homininos descuartizando el cadáver de una hembra de Mammuthus meridionalis en Fuente Nueva-3, mientras las hienas, Pachycrocuta fosilizados) de hiena. De hecho, la competencia entre homininos y hienas brevirostris, acechan | dibujo Mauricio Antón por el acceso a estos cadáveres se encuentra bien documentada al menos en un caso. Se trata del esqueleto parcial de un elefante hembra, de unos 55 años de edad a su muerte, que aparece desmembrado y rodeado parcialmente por lascas de sílex y coprolitos de hiena, de color oscuro (indicativo de que comieron la carne del animal), lo que evidencia su consumo por estos dos supercarroñeros del Pleistoceno. Dada la gran extensión del yacimiento, que cuenta con varios miles de metros cuadrados potencialmente fértiles, es muy posible que en un futuro, conforme se vaya desarrollando la excavación, aparezcan varias decenas o incluso centenares de elefantes allí acumulados (ESPIGARES; MARTÍNEZ-NAVARRO; PALMQVIST et ál., 2013).

En la lucha por el aprovechamiento de esta abundante carroña y por la supervivencia entre homininos y grandes carnívoros, en un yacimiento tan extenso como Fuente Nueva 3, es muy probable que algún congénere nuestro tuviera mala suerte y fuera cazado y matado por una hiena $u$ otro carnívoro. Por ello, es posible que en esta localidad arqueopaleontólogica se localice en un futuro algún resto humano que contribuya a mejorar el registro paleoantropológico de Orce.

Como se ha dicho, además de los registros de la cuenca de Baza y Guadix, otros yacimientos importantes correspondientes al Villafranquiense superior 


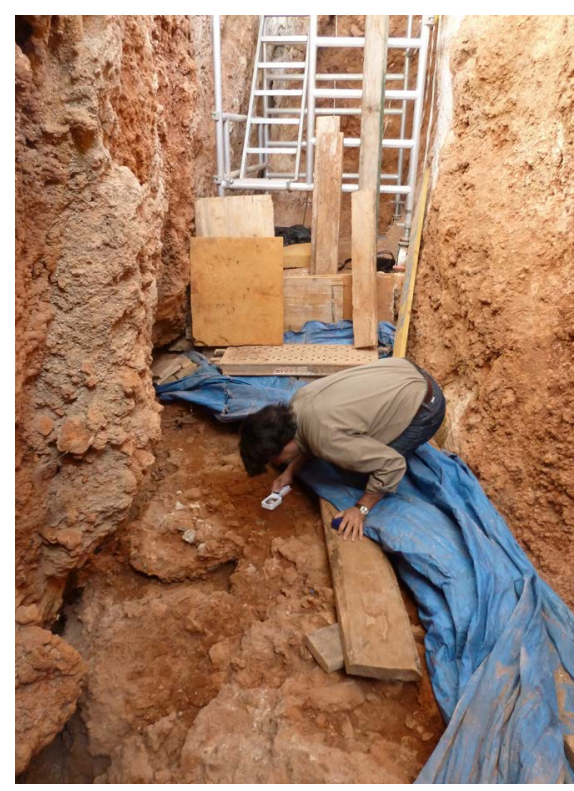

Arriba, yacimiento del Pleistoceno inferior (Villafranquiense superior) del Alto de las Picarazas (Andilla-Chelva, Valencia) | foto B. Martínez-Navarro

A la derecha, yacimiento de Incarcal (Embudo de Incarcal V) durante la excavación de septiembre de 2016, Villafranquiense superior (Crespià, Gerona) | foto B. Martínez-Navarro

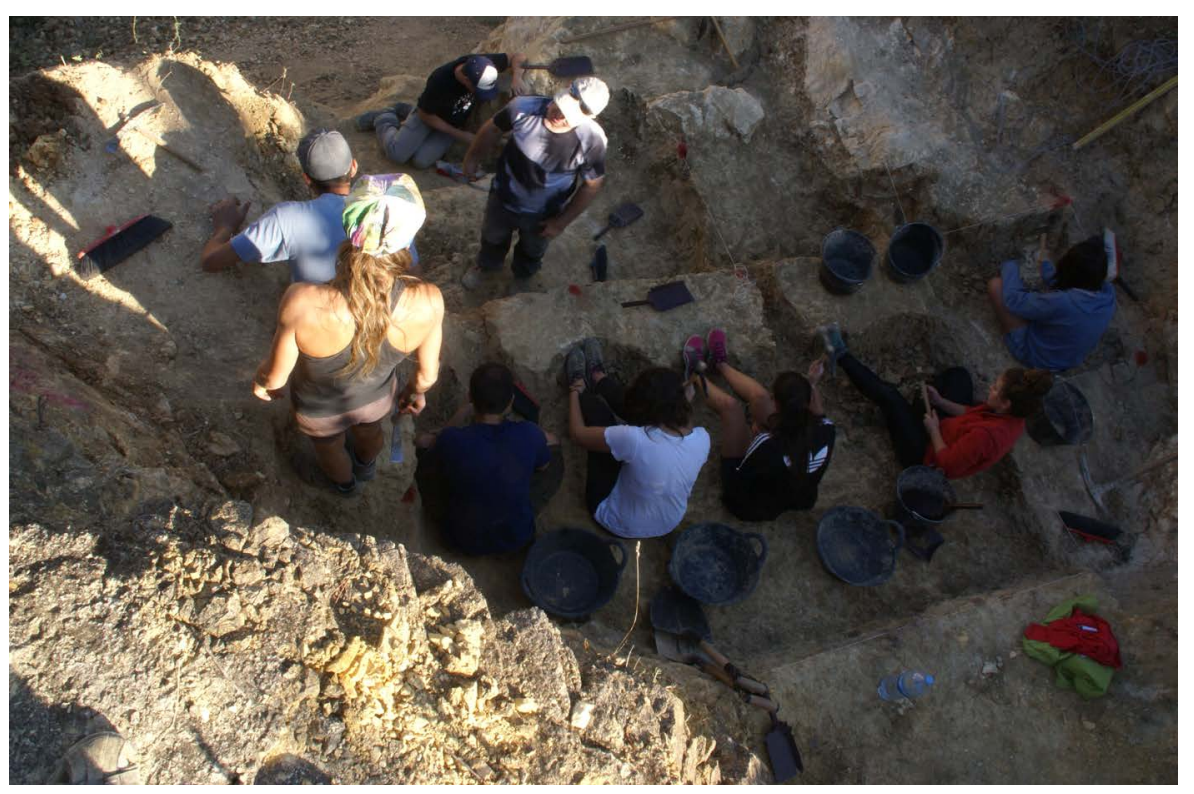

en la Península Ibérica son el de Incarcal en Crespià (Girona), donde en unos embudos kársticos se localizan abundantes restos de grandes mamíferos (Mammuthus meridionalis, Stephanorhinus hundsheimensis, Equus altidens, Hippopotamus antiquus, Bison sp., Pachycrocuta brevirostris, Homotherium latidens, Macaca sylvanus florentina y otros) (ROS-MONTOYA; MADURELLMALAPEIRA; MARTÍNEZ-NAVARRO et ál., 2012; ALBA; MADURELLMALAPEIRA; DELSON et ál., 2016), y el del Alto de las Picarazas, donde se ha citado la presencia de grandes bovinos, Bison sp. y Hemibos sp., junto a Equus altidens, Metacervocerus rhenanus, Stephanorinus etruscus, Capra alba, Soergelia minor, megacerino indet, Ursus etruscus, Lynx sp., Felis cf. lunensis y Mustela sp., conjuntamente con industrias líticas y marcas de corte y fractura sobre los huesos, que atestiguan la presencia humana muy antigua en este yacimiento, a 1,4 ó 1,5 millones de años (VICENTE GABARDA; MARTÍNEZ VALLE; GUILLEM CALATAYUD et al., 2016). También habría que añadir el yacimiento de Quibas, en Murcia, de cronología similar a Orce, donde también se localiza Macaca sylvanus (ALBA; CARLOS CALERO; MANCHEÑO et ál., 2011).

\section{EL EPIVILLAFRANQUIENSE Y LA LLEGADA DE LOS CERDOS MODERNOS A EUROPA}

El Epivillafranquiense comienza aproximadamente hace 1,1-1,2 millones de años (ROOK; MARTíNEZ-NAVARRO, 2010; MADURELL-MALAPEIRA; ROS-MONTOYA; ESPIGARES et ál., 2014; BELLUCCI; SARDELLA; ROOK, 2015) y se caracteriza por un recambio progresivo de las faunas cuaternarias 
en Europa, relacionado con el cambio climático que avecina el Pleistoceno medio y culmina medio millón de años más tarde. Por ello, en la bibliografía se conoce como la "revolución del Pleistoceno medio" (Mid-Pleistocene Revolution), caracterizable por un cambio de influencia en los factores de ciclicidad astronómica que controlan el clima de la Tierra, que pasan de estar dominados por los ciclos de oblicuidad del eje de rotación, con una frecuencia de 41 mil años (41 ka) a los resultantes de los cambios en la excentricidad orbital (100 ka), lo que desencadena los ciclos glaciares del Pleistoceno y la acumulación permanente de hielo en el Ártico.

Nuevas especies aparecen paulatinamente en el continente mientras que otras desaparecen. Este proceso culmina con la práctica extinción, al final del Pleistoceno inferior o ya en la base del Pleistoceno medio, de la mayoría de las especies Villafranquienses (por ejemplo, carnívoros como Pachycrocuta brevirostris, Megantereon whitei y Lycaon lycaonoides, los caballos Equus altidens y Equus sussenbornensis, el elefante Mammuthus meridionalis, el hipopótamo Hippopotamus antiquus, el ciervo Praemegaceros verticornis, etc.), y progresivamente van llegando otras nuevas de hábitos más generalistas, produciéndose un cambio total en el tránsito Pleistoceno inferior/ medio, entre 0,9 y 0,7 millones de años, como se explica más abajo.

La especie más significativa de todo este escenario Epivillafranquiense es el jabalí Sus scrofa (MARTÍNEZ-NAVARRO; MADURELL-MALAPEIRA; ROSMONTOYA et ál., 2015). Los cerdos, el grupo de los suidos en general y, en menor medida, sus primos americanos los pécaris, son los únicos ungulados que presentan reproducción múltiple, es decir, sus camadas están compuestas por un número de crías amplio, a veces de hasta 15 o más individuos, por lo que el potencial de multiplicación de sus poblaciones es muy elevado, en cierta manera parecido al de los roedores; sólo hay que pensar en la plaga que suponen los jabalíes actuales en muchos lugares y comarcas que han quedado desocupadas por nuestra especie. Mientras tanto, los demás ungulados presentan una tasa de reproducción mucho más limitada, con una sola cría normalmente por parto, que excepcionalmente pueden ser dos y en muy contadas ocasiones tres. Por esta causa, cuando los cerdos están presentes en los ecosistemas del pasado, es muy normal que queden registrados en las asociaciones paleontológicas, pues la tasa de fosilización se relaciona directamente con la tasa de reproducción. Es decir, a mayor tasa de reproducción (y la de los cerdos es la más alta entre los ungulados), mayor probabilidad de registro para una especie. Sin embargo, es muy significativo que en ninguno de los yacimientos de Orce (Venta Micena, Barranco León o Fuente Nueva 3), ni en todo el triángulo fosilífero que conforman OrceFuente Nueva y Venta Micena, después de más cuarenta años de investigación continuada y decenas de miles de fósiles exhumados, jamás se hayan localizado restos de cerdos. La única conclusión a la que hemos llegado es que no se encontraban presentes en las comunidades de mamíferos del 
Abajo, yacimiento del Torrent de Vallparadís, Epivillafranquiense (Terrassa, Barcelona). Arriba, excavación; debajo, detalle de una acumulación de huesos | foto J. Madurell-Malapeira

A la derecha, yacimiento Epivillafranquiense de la Boella (La Canonja, Tarragona). Defensas de Mammuthus meridionalis | foto Josep Vallverdú
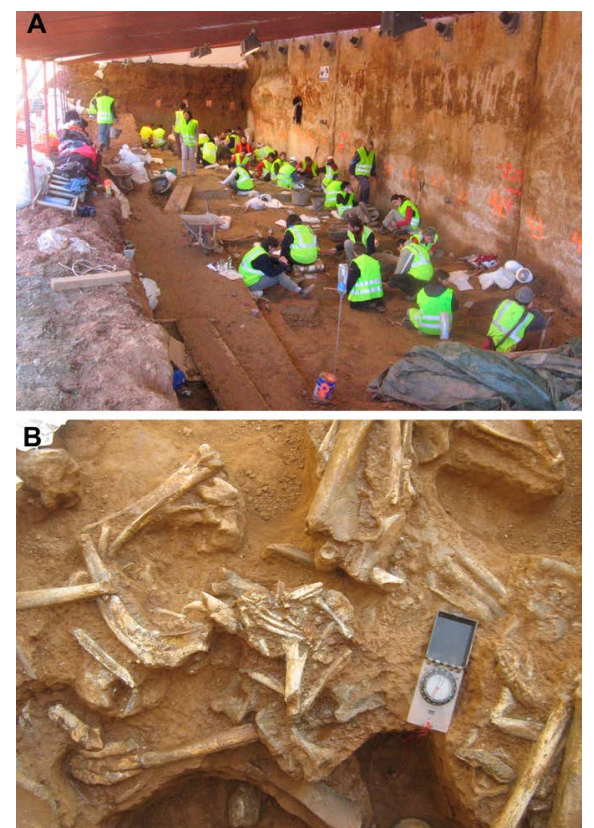

Villafranquiense superior. Curiosamente, sí hay cerdos en Europa en cronologías anteriores a 1,8 millones de años, incluso en la cuenca de Baza y Guadix en el yacimiento de Fonelas P-1, donde hay una especie designada allí como Potamochoerus magnus, la cual llaman en otras partes Sus strozzii, pero luego los cerdos desaparecen de todo el continente. Por ejemplo, en el momento faunístico de Dmanisi, en el Cáucaso, coincidiendo con la primera dispersión de los homininos africanos hacia el norte, ya han desaparecido los cerdos de Europa, pues allí no se encuentran, y no vuelven a reaparecer en nuestro continente hasta que se registran en el nivel TE9 de la Sima del Elefante de Atapuerca junto a la porción anterior de una mandíbula humana, en una cronología de 1,2 millones de años, donde se localiza una forma primitiva del cerdo moderno Sus scrofa (CARBONELL; BERMÚDEZ DE CASTRO; PARÉS et ál., 2008). A partir de esta cronología, los cerdos se generalizan y nunca más vuelven a desaparecer de Europa.

Basados en este argumento, se puede decir que los homininos llegan a Europa occidental antes que los cerdos modernos, tal y como queda demostrado en los yacimientos de Orce donde sí hay evidencias de presencia humana, como en Barranco León (1,4 millones de años) y en Fuente Nueva-3 (1,3-1,5 millones de años). Por tanto, ésta es una evidencia de que los yacimientos de Orce son más antiguos que los de Atapuerca, donde sí hay cerdos.

Como yacimientos emblemáticos en la Península Ibérica del Epivillafranquiense hay que citar dos localidades catalanas, la sección del

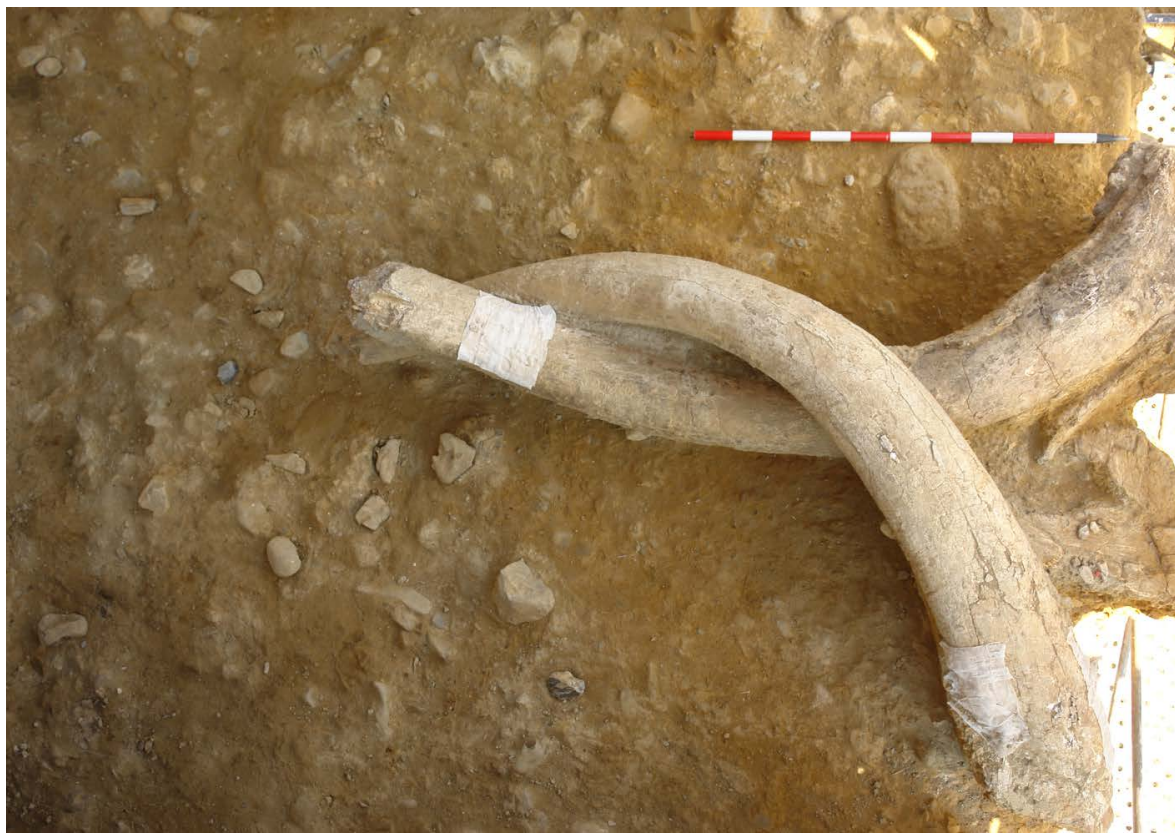


Torrent de Vallparadís, situada en el centro del casco urbano de la ciudad de Terrassa, en Barcelona, donde en una serie que abarcaría todo el Epivillafranquiense existe un extraordinario registro faunístico, excavado especialmente durante la primera década del presente siglo (MADURELLMALAPEIRA; MINWER-BARAKAT; ALBA et ál., 2010), y el de La Boella, en La Canonja, próximo a Tarragona, donde conjuntamente con un rico registro faunístico se ha localizado una industria lítica de tipo Achelense primitivo (VALLVERDÚ; SALADIÉ; ROSAS et ál., 2014).

Es también en el Epivillafranquiense cuando se localiza en el sureste de la Península Ibérica, concretamente en Cueva Victoria, en Cartagena, localidad datada en 0,9 millones de años, una especie de mono gigante, un cercopitécido parecido a los babuinos gelada actuales, de unos $50 \mathrm{~kg}$ de masa y origen africano. Se trata de Theropithecus oswaldi (GIBERT; RIBOT; GIBERT et ál., 1995; MARTÍNEZ-NAVARRO; CLARET; SHABEL et ál., 2005; MARTÍNEZ-NAVARRO; PALMQVIST; SHABEL et ál., 2008; FERRÁNDEZCAÑADELL; RIBOT; GIBERT, 2014), un animal bien conocido y ampliamente registrado en África, pero muy escaso fuera de dicho continente. Por el momento, además de en este yacimiento murciano, se ha identificado en Israel, en la localidad arqueopaleontológica de 'Ubeidiya, y en Mirzapur, en los montes Siwaliks de la India. La explicación ecológica de su presencia en Eurasia es una incógnita de difícil resolución. También en la provincia de Murcia, muy cerca de Andalucía, en el término municipal de Caravaca de la Cruz, hay que citar el yacimiento de Cueva Negra de la Encarnación, datado justo en el límite terminal del Pleistoceno inferior (SCOTT; GIBERT, 2009). Allí se ha citado la presencia de hogares, que se corresponderían con los registros de domesticación del fuego más antiguos de toda Europa (WALKER; LÓPEZ-MARTÍNEZ; CARRIÓN GARCÍA et ál., 2012).

En Andalucía es interesante señalar el yacimiento kárstico de El Chaparral, en Villaluenga del Rosario (Cádiz), datado en aproximadamente 1,0 millones de años (GILES PACHECO; SANTIAGO; MARÍA GUTIÉRREZ et ál., 2011), además de otros yacimientos en la cuenca de Guadix-Baza, donde especialmente destaca la localidad de Huéscar-1, en la que se ha citado una fauna correspondiente al Epivillafranquiense, de una edad aproximada de 0,8-1,0 millones de años, integrada por diversos grandes mamíferos, entre ellos un cánido de tamaño medio, un hiénido, un jaguar (Panthera gombaszoegensis), un tigre de dientes de sable de gran tamaño (Homotherium sp.), el hipópotamo Hippopotamus major (sinónimo de H. antiquus), un proboscídeo, dos especies de caballos, Equus altidens y Equus sussenbornensis (las mismas que en Barranco León y Fuente Nueva-3), un rinoceronte, una cabra y un ciervo de gran tamaño, conjuntamente con el registro de roedores, que son los que han permitido precisar la cronología del yacimiento (ALBERDI; ALCALÁ; AZANZA et ál., 1989). Asimismo, en 2003 se localizó industria lítica (MARTÍNEZ-NAVARRO; TORO MOYANO; ROS-MONTOYA et ál., 2006). 


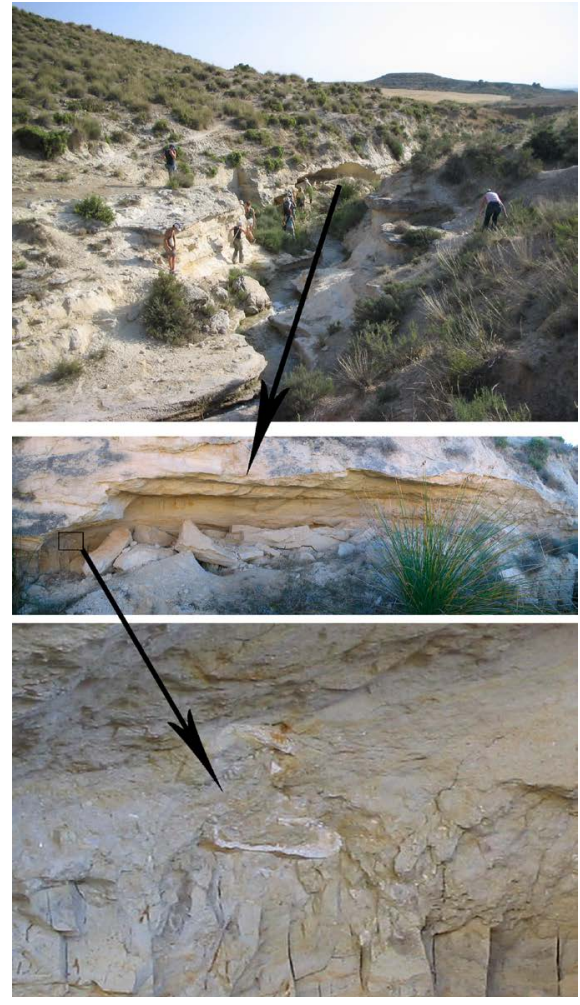

Yacimiento Epivillafranquiense de Huéscar 1 (Granada). Arriba, vista general; centro, desprendimiento a causa de la gran erosión que sufre el afloramiento; abajo resto óseo indeterminado in situ | foto S. Ros-Montoya
Sin embargo, conviene indicar que esta localidad se ha datado recientemente por la técnica de luminiscencia en aproximadamente 0,5 millones de años (DEMURO; ARNOLD; PARES et ál., 2015). Es evidente que la lista faunística y la datación numérica no se corresponden.

En España, el yacimiento emblemático de esta cronología del Pleistoceno inferior terminal es sin duda el nivel TD6 de la Gran Dolina de Atapuerca en Burgos, donde se describió la especie humana Homo antecessor (BERMÚDEZ DE CASTRO; ARSUAGA; CARBONELL et ál., 1997), nivel datado en aproximadamente 0,9 millones de años. El incremento de la población humana en la Península Ibérica (y, por extensión, en Europa) es notable, pues los yacimientos con evidencias de presencia humana se multiplican.

\section{EL PLEISTOCENO MEDIO}

En el tránsito del Pleistoceno inferior al medio (0,9-0,7 millones de años), los ciclos climáticos de cien mil años se imponen y el rigor climatológico se acentúa hasta la actualidad.

Es en este momento cuando, con singulares excepciones como el tigre de dientes de sable Homotherium latidens, que se perpetúa hasta bien entrado el Pleistoceno medio, prácticamente se han extinguido todos los taxones llamados villafranquienses y aparecen las faunas llamadas galerienses, que toman su nombre del yacimiento italiano de Ponte Galeria, en las proximidades de Roma. A partir de este momento comienzan a dominar especies más generalistas, con capacidad de sobrevivir a los cambiantes rigores climáticos, donde se alternan, cíclicamente, periodos cálidos y húmedos con otros muy fríos y secos. Estas nuevas especies, que han ido llegando sucesivamente desde que comenzó el Epivillafranquiense, integran, además de los cerdos, a nuevos carnívoros, como la hiena manchada cazadora y carroñera Crocuta crocuta, y la hiena carroñera rayada Hyaena hyaena, el león Panthera leo y el leopardo Panthera pardus, todos ellos procedentes de África. También colonizan el continente nuevos herbívoros: dos especies de elefantes, una procedente de Asia, adaptada a ambientes esteparios (Mammuthus trogontherii), y otra procedente de África, adaptada a una alimentación de tipo generalista [Elephas (Palaeoloxodon) antiquus], un nuevo équido, ancestro directo del caballo doméstico (Equus ferus), el ciervo común o venado (Cervus elaphus), etc. Algunas de estas nuevas especies se perpetúan en nuestro continente hasta el final del Pleistoceno e incluso unas pocas llegan a sobrevivir hasta la actualidad.

En la cuenca de Guadix-Baza, en una cronología ligeramente más reciente, próxima a 0,7-0,8 millones de años, se encuentra el yacimiento de Cúllar Baza-1 (hoy Cúllar, a secas) (RUIZ-BUSTOS, 1976; ALBERDI; DIAGO, 
2009). Dicha localidad arqueopaleontológica conserva aún algunas especies epivillafranquienses, tales como los caballos Equus altidens y Equus sussenbornensis, y el rinoceronte Stephanorhinus hundsheimensis.

Ya entrado el Pleistoceno medio, en torno a 0,5-0,6 millones de años, se produce también la llegada a Europa de una especie muy significativa. Se trata del uro Bos primigenius, el ancestro de los actuales toros y vacas domésticos, que es una especie evolucionada en África durante el Pleistoceno inferior, cuyo origen es el búfalo de Olduvai, el llamado Pelorovis oldowayensis, descrito en 1928 por un paleontólogo alemán llamado Reck (MARTíNEZNAVARRO; PÉREZ-CLAROS; PALOMBO et ál., 2007).

Bos primigenius coloniza Europa en un viaje desde África realizado en paralelo con los homininos portadores de industrias líticas achelenses evolucionadas, que darán lugar a las poblaciones europeas de Homo heidelbergensis, a partir de las que evolucionarán luego los neandertales. Desde hace 0,5 millones de años hasta la actualidad la cantidad de registros arqueopaleontológicos en Europa en general, y en España en particular, se multiplica. La cita y descripción de todos ellos en este capítulo es imposible, pues son muchos y muy interesantes. La presencia de industria lítica achelense evolucionada es general en todas partes. Los yacimientos con fauna y, algunos de ellos, también con restos humanos, son comunes, destacando los de Sima de los Huesos y Galería en la Sierra de Atapuerca (ARSUAGA; MARTÍNEZ; GRACIA et ál., 1993; GARCÍA-MEDRANO; CÁCERES; OLLÉ et ál., 2017), o el nuevo hallazgo realizado en el yacimiento portugués de la Gruta da Aroeira en Portugal, datado en 0,4 millones de años (DAURA; SANZ; ARSUAGA et ál., 2017).

En este contexto habría que hacer referencia a la cueva de Letzitxiki en Mondragón, Guipúzcoa (ARRIOLABENGOA; IRIARTE; ARANBURU et ál., 2015), Bolomor en Tavernes de la Valldigna, Valencia (SAÑUDO; BLASCO; FERNÁNDEZ PERIS 2016), Cueva Horá en Darro y la Carihuela en Píñar, ambas en Granada (BOTELLA LÓPEZ, 1987; VEGA-TOSCANO; HOYOS; RUIZ-BUSTOS et ál., 1988), o la Cueva del Ángel en Lucena, Córdoba (BARROSO RUÍZ; BOTELLA ORTEGA; CAPARRÓS et ál., 2011).

Dentro de estas cronologías hay que incluir también el yacimiento en terraza de Ambrona en Soria, con abundante presencia del elefante Palaeoloxodon antiquus (SANTONJA GÓMEZ; PÉREZ GONZÁLEZ; RUIZ ZAPATA et ál., 2005)

En la cuenca de Baza y Guadix se encuentra el famoso yacimiento de la Solana del Zamborino, en el municipio de Fonelas, próximo a Guadix, que se excavó en los años setenta por Miguel Botella, de la Universidad de Granada. En esta localidad arqueopaleontológica se ha identificado una amplia lista 
Yacimiento del Pleistoceno medio de la Solana del Zamborino (Fonelas, Granada) | foto B. MartínezNavarro

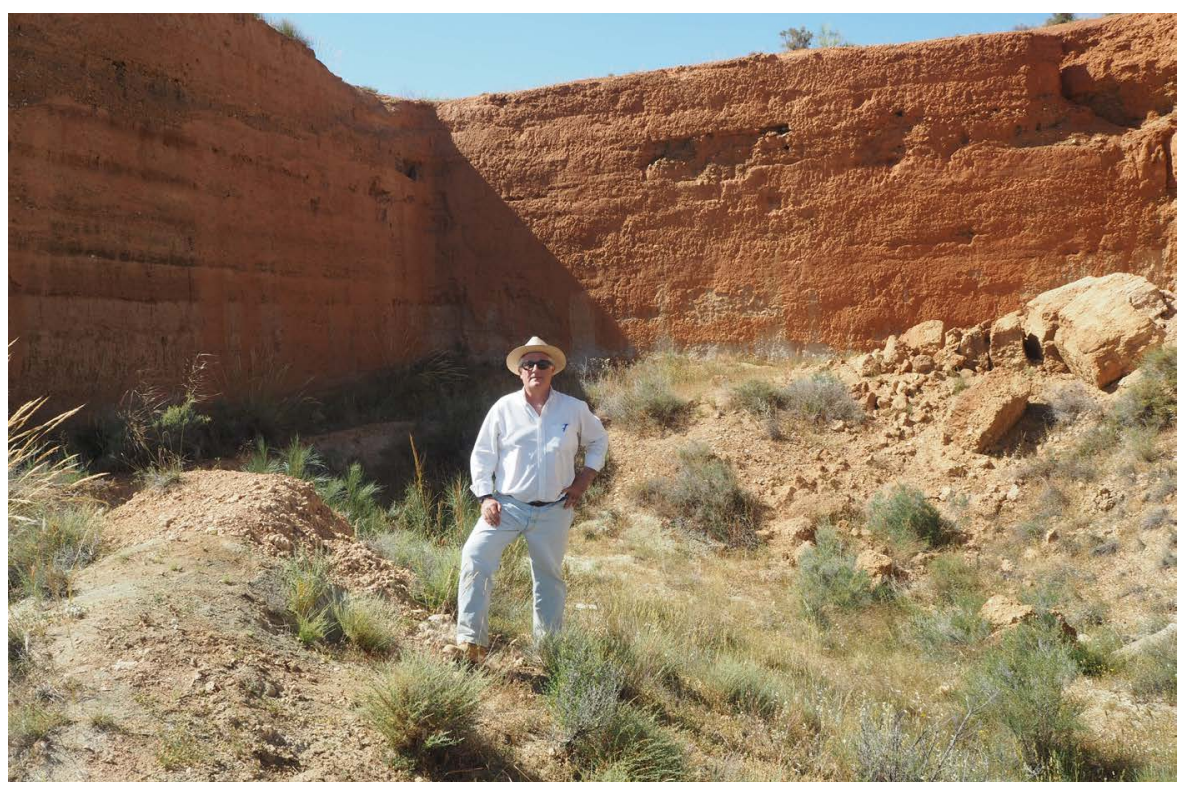

faunística, compuesta por especies modernas, muchas de ellas supervivientes en la actualidad, que fueron descritas en un principio en Martín-Penela (1988) y posteriormente adaptadas a una nomenclatura más moderna en Ruiz-Bustos (1999). El registro paleontológico contiene al mono de berbería Macaca sylvanus, que habita actualmente en Gibraltar (bien representado a lo largo del Pleistoceno en la Península en diversos yacimientos, como ya se ha dicho, incluido el Pleistoceno medio, por ejemplo la cueva de Bolomor, en Valencia, arriba citada), al mamut de estepa Mammuthus trogontherii, al elefante generalista de origen africano Elephas (Palaeoloxodon) antiquus, al caballo moderno Equus caballus torralbae, al rinoceronte de pradera Stephanorhinus hemitoechus, al venado Cervus elaphus, al corzo Capreolus capreolus, al gamo Dama sp., al toro Bos primigenius, al bisonte de pradera Bison priscus, al hipopótamo moderno Hippopotamus cf. amphibius, al jabalí Sus scrofa, al lobo Canis lupus, al león de las cavernas Panthera leo spelaea, al lince ibérico Lynx cf. pardinus y al gato montés Felis sylvestris.

Esta lista faunística es coherente con una edad de 0,3-0,5 millones de años (JIMÉNEZ-ARENAS, SANTONJA, BOTELLA et ál., 2011), según se ha confirmado recientemente tras un análisis paleomagnético exhaustivo (ÁLVAREZ-POSADA; PARÉS; SALA et ál., 2017).

\section{EL PLEISTOCENO SUPERIOR}

El Pleistoceno superior está básicamente registrado en cuevas y terrazas de ríos, y su abundancia es muy importante a lo largo de toda la geografía ibé- 
rica, por lo que la cita de todos los yacimientos es imposible en la extensión de este escrito.

A nivel humano, estos yacimientos están ligados a la presencia de los neandertales hasta su extinción, entre hace unos 40 y 30000 años, según diversos autores, y a nuestra especie desde su llegada coincidiendo con la extinción de los primeros.

Desde entrado el Pleistoceno medio y durante el Pleistoceno superior, en las latitudes septentrionales del planeta, incluida Europa, la fauna se caracteriza por la alternancia de especies adaptadas al frío, que dominan el continente durante los momentos glaciales, cuyos máximos exponentes son el mamut y el rinoceronte lanudos (Mammuthus primigenius y Coelodonta antiquitatis, respectivamente), pero además hay que incluir el ciervo gigante conocido como el "alce irlandés" (Megaloceros giganteus), el reno (Rangifer tarandus), el bisonte (Bison bonasus), el antílope saiga (Saiga tatarica), o el buey almizclero (Ovibos moschatus), entre otros.

La presencia de faunas adaptadas a climas fríos, dadas las características geográficas de nuestra península, es menos abundante en España que en otros países situados en latitudes más septentrionales de Europa. Aun así, la presencia de estas especies no es anómala durante el Pleistoceno superior, especialmente en las cuevas de la mitad norte a lo largo de la Cornisa Cantábrica, de los Pirineos y de las cordilleras Central e Ibérica. Como ejemplo se puede citar la cueva de l'Arbreda, en Serinyà, Gerona (ESTÉVEZ, 1987). Mientras tanto, el sur y las zonas del Levante se han comportado como refugios climáticos de especies adaptadas a climatologías benignas, como por ejemplo el toro (Bos primigenius), el rinoceronte de pradera (Stephanorhinus hemitoechus), o el elefante de defensas largas y rectilíneas (Palaeoloxodon antiquus), en contraposición al bisonte, al rinoceronte lanudo o al mamut lanudo, respectivamente, todos ellos de clima frío.

En este contexto, cabe decir que en el Pleistoceno superior tardío el frío llegó a ser muy intenso y parte de esta fauna se expandió hasta el extremo más meridional de la Península. Así, en un momento álgido del hielo, en torno a una cronología entre 40 y 30000 años de antigüedad, se han localizado restos fósiles de mamut lanudo en las turberas de El Padul, ya en la falda oriental de Sierra Nevada, a escasos kilómetros al sur de Granada (ROS-MONTOYA, 2006; ÁLVAREZ-LAO; KAHLKE; GARCÍA et ál., 2009). Este último dato indica cuán importantes han sido los cambios climáticos a lo largo del Cuaternario, ahora que está tan de moda el tema gracias a las alteraciones antrópicas del clima, con amplios glaciares recorriendo la geografía europea en los momentos de menor temperatura, los cuales afectaban de manera significativa hasta las regiones montañosas situadas más al sur del continente. 
Curiosamente, el registro de Mammuthus primigenius en el Padul coincide con la extinción de Homo neanderthalensis en la Península Ibérica, cuyos últimos registros se encuentran precisamente en el sur. El Pleistoceno superior tardío y el Holoceno se caracterizan por la extinción masiva y sucesiva de la megafauna, y posteriormente de otras especies de menor tamaño, extinción que se proyecta hasta la actualidad, pues siguen siendo muchas las especies cuyo ocaso se está produciendo en estos momentos. Esta extinción comienza de manera coincidente o justo después de la colonización por parte del hombre anatómicamente moderno, Homo sapiens, de los distintos territorios, como es manifiesto en España. Este es un tema en continuo debate, sobre cuáles son las causas de la desaparición de la megafauna y, también, sobre cuáles son las causas que provocan la extinción final de los neandertales. En nuestra opinión, Homo sapiens es el causante fundamental de la desaparición de la fauna y de los neandertales, gracias a su capacidad cinegética sin parangón en momentos precedentes a su llegada. La caza masiva, especialmente en el caso de los ungulados de tamaño medio a grande, no da tiempo a que los individuos de las distintas especies se reproduzcan suficientemente como para contrarrestar la mortandad provocada por nuestros antepasados. La reproducción en el caso de los grandes animales es muy costosa, con largos tiempos de gestación, lactancia y menarquia, al igual que en los humanos, incluidos los neandertales, que deben competir con los sapiens por los recursos. La llegada del hombre moderno desequilibra las poblaciones de las distintas especies, disminuyendo el número de individuos y derivando finalmente en la fatalidad, en su ocaso (HORTOLÀ; MARTÍNEZ-NAVARRO, 2013).

Los yacimientos más importantes con presencia de fauna y neandertales en España son el del Sidrón en Asturias, Lezitxiki en el País Vasco, el Abric Romaní en Cataluña, El Tossal de la Font, Bolomor y Cova Negra en la Comunidad Valenciana, Pinilla del Valle en Madrid, la Sima de las Palomas en Murcia, Cueva Horá, La Carihuela, o el Boquete de Zafarraya en Andalucía, más las cuevas de Gibraltar.

Los registros con presencia de Paleolítico superior asociado a fauna son muy abundantes y están distribuidos por toda la Península.

\section{EL PATRIMONIO PALEONTOLÓGICO PLIO-PLEISTOCÉNICO Y SU EXPLOTACIÓN EN ESPAÑA}

Como se ha explicado, son muchos y muy buenos los registros paleontológicos de cronologías recientes en nuestro país. Estos yacimientos están muy bien estudiados en muchos casos y su conocimiento científico es muy alto, siendo publicados en las mejores revistas paleontológicas, arqueológicas, geológicas y de ámbito más generalista (Nature, Science, PNAS, PlosONE, 
Quaternary Science Reviews, Palaeo3, Journal of Human Evolution, etc.). Sin embargo, el conocimiento científico no siempre se corresponde con el impacto mediático y con la explotación del patrimonio gracias al fomento del turismo cultural de calidad. Son pocos los yacimientos bien publicitados y adaptados para ser visitados que estén puestos en explotación turística de manera satisfactoria.

La excepción más importante la constituyen los yacimientos de la Sierra de Atapuerca en Burgos, donde en unos registros únicos por el enorme número de fósiles humanos allí localizados, asociados a una importante información paleontológica y arqueológica, se ha realizado una investigación de excelencia acompañada de una estrategia mediática que ha hecho de este patrimonio un lugar de referencia mundial, acompañada de la declaración por la UNESCO como Patrimonio de la Humanidad en el año 2000. Ello ha contribuido a convencer a la sociedad y a los políticos para crear las infraestructuras e instituciones necesarias en torno a este gran proyecto, tales como el Museo de la Evolución y el Centro Nacional de Investigación sobre la Evolución Humana-CENIEH en Burgos, la Fundación Atapuerca en Ibeas de Juarros y los distintos centros de recepción e interpretación en la Sierra de Atapuerca. Esta suma ha hecho que los yacimientos de Atapuerca estén permanentemente en los medios de comunicación y que los visitantes a los mismos se cuenten por varios cientos de miles cada año, convirtiendo este patrimonio en un recurso económico y social extraordinario para Burgos y su entorno.

Otros intentos de explotación del patrimonio paleontológico se han hecho en diversos yacimientos, tales como los de la cuenca de Baza y Guadix en Granada, especialmente en Orce donde existe el mayor patrimonio paleontológico del Pleistoceno inferior de Europa, y luego en Fonelas a través de un proyecto de Geoparque para las altiplanicies granadinas que está actualmente en proceso de tramitación. Desgraciadamente, el éxito de estos intentos ha sido por el momento relativo.

El ejemplo de Atapuerca debe servir como acicate para que otras localidades paleontológicas tomen nota y este patrimonio se explote adecuadamente de cara al futuro.

\section{CONCLUSIONES}

Esta revisión cronológica, necesariamente limitada, del registro paleobiológico de la Península Ibérica es suficiente para mostrar la importancia de un patrimonio natural sin igual en todo el continente europeo. La abundancia de localidades paleontológicas constituye un libro abierto para el estudio de las sucesivas comunidades de mamíferos continentales que habitaron el sur de

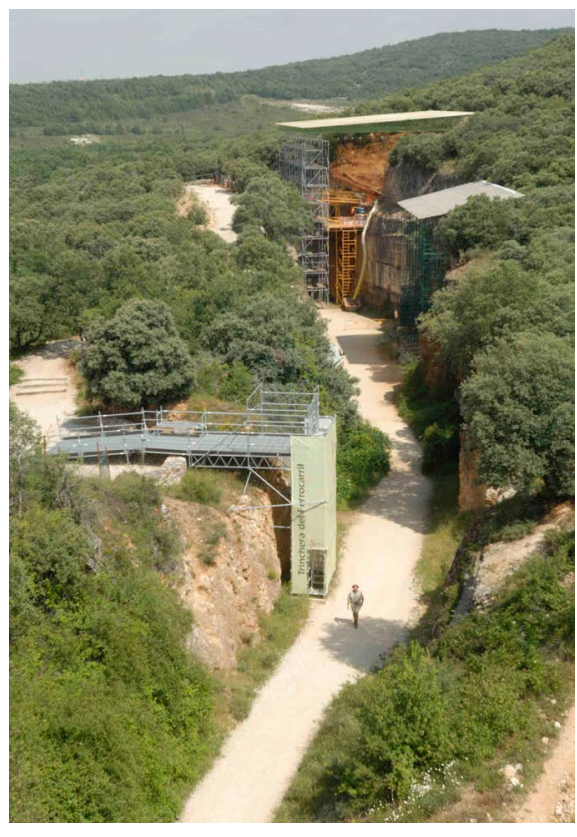

Trinchera del Ferrocarril en la Sierra de Atapuerca, donde se encuentran varios de los yacimientos del complejo kárstico (Sima del Elefante, Galería, Dolina) | foto Proyecto Atapuerca-IPHES 
Europa durante todo el Plio-Pleistoceno, desde hace 5-6 millones de años hasta prácticamente la actualidad. Las condiciones geológicas de nuestro país, la enorme cantidad de afloramientos con restos de faunas pretéritas, la extensión de los estratos que albergan los fósiles, la densidad de restos, su buen estado de conservación y su accesibilidad, hacen de España un paraíso para el conocimiento de los ecosistemas del pasado. A ello hay que sumar, además, los registros más antiguos con presencia humana de toda Europa, basados en el hallazgo de restos fósiles e ingentes asociaciones de industria lítica. Gracias a ello, se pueden reconstruir los paleoambientes con una fidelidad que no es posible en otros lugares.

El conocimiento y la divulgación de este patrimonio sin igual en Europa debe implementarse con una estrategia clara y prioritaria con vistas a su explotación social y económica.

\section{Agradecimientos}

Al equipo editorial de la revista $\mathrm{PH}$ por habernos invitado a contribuir con este trabajo al volumen monográfico sobre patrimonio paleontológico. Este estudio ha sido financiado por los proyectos MINECO CGL2016-80975-P y CGL2016-78577-P, CGL-2014-54373-P, así como por los grupos de investigación de la Generalitat de Cataluña 2017 SGR 859 y SGR 116 GRC, y el grupo de investigación de la Junta de Andalucía RNM-146. 


\section{BIBLIOGRAFÍA}

- AGUSTÍ, J.; BLAIN, H.-A.; FURIÓ, M.; MARFÁ, R. (DE); MARTÍNEZ-NAVARRO, B.; OMS, O. (2013) Early Pleistocene environments and vertebrate dispersals in Western Europe: the case of Barranco de los Conejos (Guadix-Baza Basin, SE Spain). Quaternary International, vol. 295, 2013, pp. 59-68

- AGUSTÍ, J.; OMS, O.; REMACHA, E. (2001) Long Plio-Pleistocene Terrestrial Record of Climate Change and Mammal Turnover in Southern Spain. Quaternary Research, 56, 2001, pp. 411-418

- ALBA, D. M.; CARLOS-CALERO, J. A.; MANCHEÑO, M. A.; MONTOYA, P.; MORALES, J.; ROOK, L. (2011) Fossil remains of Macaca sylvanus florentina (Cocchi, 1872) (Primates, Cercopithecidae) from the Early Pleistocene of Quibas (Murcia, Spain). Journal of Human Evolution, 61 (6), 2011, pp. 703-718

- ALBA, D. M.; MADURELL-MALAPEIRA, J.; DELSON, E.; VINUESA, V.; SUSANNA, I.; ESPIGARES, M. P.; ROSMONTOYA, S.; MARTÍNEZ-NAVARRO, B. (2016) First record of macaques from the Early Pleistocene of Incarcal (NE Iberian Peninsula). Journal of Human Evolution, 96, 2016, pp. 139-144

- AlBerdi, M. T.; ALONSO, M. A. (2009) Cúllar-Baza 1. En MARTÍNEZ-NAVARRO, B.; TORO MOYANO, I.; PALMQVIST, P.; AGUSTÍ, J. (ed.) (2009) The Quaternary of southern Spain: a bridge between Africa and the Alpine domain - Fieltrips Guide. Orce, pp. 20-128

- ALBERDI, M. T.; ALCALÁ, L. (1989-90) El género hipparion en la fosa del Alfambra-Teruel. Paleontologia $i$ Evolució, 23, 1989-90, pp. 105-109

- ALBERDI, M. T.; ALCALÁ, L.; AZANZA, B., CERDEÑO, E.; MAZO, A. V.; MORALES, J.; SESÉ, C. (1989) Consideraciones bioestratigráficas sobre la fauna de Vertebrados fósiles de la cuenca de Guadix-Baza (Granada, España). En ALBERDI, M. T.; BONADONNA, F. P. Geología y Paleontología de la Cuenca de Guadix-Baza. Madrid: CSIC-Museo Nacional de Ciencias Naturales, 1989, pp. 347-355 (Trabajos sobre el Neógeno-Cuaternario; 11)

- AlBERDI, M. T.; AZANZA, B.; CERVANTES, E. (ed.) (2016) Villarroya, Yacimiento Clave de la Paleontología Riojana [Villarroya, Key Site of La Rioja Palaeontology]. Logroño: Gobierno de la Rioja, 2016 (Ciencias de la Tierra; 34)

- AlCALÁ, L.; MORALES, J.; MOYÁ-SOLÁ, S. (198990) El registro fósil neógeno de los bóvidos (Artiodactyla, Mammalia) de España. Paleontologia i Evolució, 23, 198990 , pp. $67-73$

- AlONSO DIÁGO, M. A.; HOYOS GÓMEZ, M.; ALBERDI, M. T. (2002) Tafonomía y ambiente sedimentario del yacimiento de Huélago. Estudios Geológicos, 58, 2002, pp. 11-25
- ÁlVAREZ-LAO, D, J.; KAHLKE, R.-D.; GARCíA, N.; MOL, D. (2009) The Padul mammoth finds - On the southernmost record of Mammuthus primigenius in Europe and its southern spread during the Late Pleistocene. Palaeogeography, Palaeoclimatology, Palaeoecology, vol. 278, 2009, pp. 57-70

- ÁlVAREZ-POSADA, C.; PARÉS, J. M.; SALA, R.; VISERAS, C.; PLA-PUEYO, S. (2017) New magnetostratigraphic evidence for the age of Acheulean tools at the archaeo-palaeontological site "Solana del Zamborino" (Guadix - Baza Basin, S Spain). Scientific Reports 7: $13495<$ https://doi.org/10.1038/s41598-017-140 24-5>

- ARAMBOURG, C.; PIVETEAU, J. (1929) Les vertébrés du Pontien de Salonique. Annales de Paléontologie, 18, 1929, pp. 59-138

- ARRIBAS, A.; PALMQVIST, P. (1998) Taphonomy and paleoecology of an assemblage of large mammals: hyaenid activity in the lower Pleistocene site at Venta Micena (Orce, Guadix-Baza Basin, Granada, Spain). Geobios, 31(suppl.), 1998, pp. 3-47

- ARRIBAS, A.; GARRIDO, G.; VISERAS, C.; SORIA, J. M.; PLA, S.; SOLANO, J. G.; GARCÉS, M.; BEAMUD, E.; CARRIÓN, J. S. (2009) A Mammalian Lost World in Southwest Europe during the Late Pliocene. PlosONE 4(9): e7127. <https://doi.org/10.1371/journal.pone.0007127>

- ARRIOLABENGOA, M.; IRIARTE, E.; ARANBURU, A.; YUSTA, I.; ARRIZABALAGA, A. (2015) Provenance study of endokarst fine sediments through mineralogical and geochemical data (Lezetxiki II cave, northern Iberia). Quaternary International, vol. 364, 2015, pp. 231-243 <https://doi.org/10.1016/j.quaint.2014.09.072>

- ARSUAGA, J. L.; MARTínEZ, I.; GRACIA, A.; CARRETERO, J. M.; CARBONELL, E. (1993) Three new human skulls from the Sima de los Huesos Middle Pleistocene site in Sierra de Atapuerca, Spain. Nature, 362, 1993, pp. 534-537 <https://doi.org/10.1038/362534a0>

- AZANZA, B.; MENÉNDEZ, E. (1989-90) Los ciervos fósiles del neógeno español. Paleontologia i Evolució, 23, 1989-90, pp. 75-82

- AZZAROLI, A. (1983) Quaternary mammals and the end-villafranchian dispersal event- a turning point in the history of Eurasia. Palaeogeography, Palaeoclimatology, Palaeoecology, 44, 1983, pp. 117-139

- AZZAROLI, A. (1995) The "elephant-Equus" and the "end- Villafranchian" events in Eurasia. En VRBA, E. S.; DENTON, G. H.; PARTRIDGE, T. C.; BURCKLE, LL. H. (ed.) Paleoclimate and Evolution, with Emphasis on Human Origins. New Haven and London: Yale University Press, 1995, pp. 311-318 
- BAILÓN, S. (1992) Escamosos (Reptilia) fósiles del yacimiento de Moreda (Plioceno medio/superior, Granada, España). Revista Española de Paleontología, Extra, 1992, pp. 11-15

- BARRoso RUIZ, C. (coord.) (2003) El Pleistoceno superior de la Cueva del Boquete de Zafarraya. Sevilla: Consejería de Cultura, 2003

- BARROSO RUIZ, C.; BOTELLA ORTEGA, D.; CAPARRÓS, M.; LUMLEY, H. (DE) (2011) The Cueva del Angel (Lucena, Spain): An Acheulean hunters habitat in the South of the Iberian Peninsula. Quaternary International, 243 (1), 2011, pp. 105-126 <https://doi.org/10.1016/j. quaint.2011.02.021>

- BELlUCCI, I.; SARDELLA, R.; ROOK, L. (2015) Large mammal biochronology framework in Europe at Jaramillo: The Epivillafranchian as a formal biochron. Quaternary International, 389, 2015, pp. 84-89 <https://doi. org/10.1016/j.quaint.2014.11.012>

- BERMÚdeZ DE CASTRO, J. M.; ARSUAGA, J. L.; CARBONELL, E.; ROSAS, A.; MARTÍNEZ, I.; MOSQUERA, M. (1997) A hominid from the Lower Pleistocene of Atapuerca, Spain: possible ancestor to Neandertals and modern humans". Science, 276, 1997, pp. 1392-1395

- BOTELLA LÓPEZ, M. (1987) Memoria de los trabajos realizados en el yacimiento arqueológico de Cueva Horá (Darro, Granada) durante 1985. En Anuario Arqueológico de Andalucía, 1985, II. Actividades Sistemáticas. Sevilla: Consejería de Cultura, 1987, pp. 214-215

- CAMPENY VALL-LLOSERA, G.; GÓMEZ DE SOLER, B. (ed.) (2010) El Camp dels Ninots. Rastres de l'Evolució. Caldes: Ajuntament de Caldes de Malavella, Institut Català de Paleoecologia Humana i Evolució Social (IPHES )

- carbonell, E.; BERMúdeZ dE CASTRO, J. M.; PARÉS, J. M.; PÉREZ-GONZÁLEZ, A.; CUENCABESCÓS, G.; OLLÉ, A.; MOSQUERA, M.; HUGUET, R.; VAN DER MADE, J.; ROSAS, A.; SALA, R.; VALLVERDÚ J.; GARCÍA, N.; GRANGER, D. E.; MARTINÓN-TORRES, M.; RODRÍGUEZ, X. P.; STOCK, G. M.; VERGÈS, J. M.; ALLUÉ, E.; BURJACHS, F.; CÁCERES, I.; CANALS, A.; BENITO, A.; DÍEZ, C.; LOZANO, M.; MATEOS, A.; NAVAZO, M.; RODRÍGUEZ, J.; ROSELL, J.; ARSUAGA, J. L. (2008) The first hominin of Europe. Nature, 452, 2008, pp. 465-469 <https://doi.org/10.1038/nature06815>

- DAURA, J.; SANZ, M.; ARSUAGA, J. L.; HOFFMANN, D. L.; QUAM, R. M.; ORTEGA, M. C.; SANTOS, E.; GÓMEZ, S.; RUBIO, A.; VILLAESCUSA, L.; SOUTO, P.; MAURICIO, J.; RODRIGUES, F.; FERREIRA, A.; GODINHO, P.; TRINKAUS, E.; ZILHÃO, J. (2017) New Middle Pleistocene hominin cranium from Gruta da Aroeira (Portugal). PNAS 114 (13), 2017, pp. 3397-3402 <https://doi.org/10.1073/ pnas.1619040114>
- DAURA, J.; SANZ, M.; SUBIRÀ, M. E.; QUAM, R. FULLOLA, J. M.; ARSUAGA, J. L. (2005) A Neanderthal mandible from the Cova del Gegant (Sitges, Barcelona, Spain). Journal of Human Evolution, 49, 2005, pp. 56-70 <https://doi.org/10.1016/j.jhevol.2005.03.004>

- DEMURO, M.; ARNOLD, L. J.; PARÉS, J. M.; SALA, R. (2015) Extended-range luminescence chronologies suggest potentially complex bone accumulation histories at the Early-to-Middle Pleistocene palaeontological site of Huéscar-1 (Guadix-Baza basin, Spain). Quaternary International, 389, 2015, pp. 191-212 <https://doi. org/10.1016/j.quaint.2014.08.035>

- ESPIGARES, M.P.; MARTÍNEZ-NAVARRO, B.; PALMQVIST, P.; ROS-MONTOYA, S.; TORO, I.; AGUSTÍ, J.; SALA, R. (2013) Homo vs. Pachycrocuta: Earliest evidence of competition for an elephant carcass between scavengers at Fuente Nueva-3 (Orce, Spain). Quaternary International, 295, 2013, pp. 113-125 <https://doi. org/10.1016/j.quaint.2012.09.032>

- ESTÉVEZ, J. (1987) La fauna de l'Arbreda (sector Alfa) en el conjunt de faunes del Pleistocè Superior. CYPSELA VI, 1987, pp. 73-87

- FERRÀNDEZ-CAÑADELL, C.; RIBOT, F:; GIBERT, LL. (2014) New fossil teeth of Theropithecus oswaldi (Cercopithecoidea) from the Early Pleistocene at Cueva Victoria (SE Spain). Journal of Human Evolution, 74, 2014 , pp. 55-66

- FINLAYSON, C.; GILES PACHECO, F.; RODRÍGUEZVIDAL, J.; FA, D. A.; GUTIÉRREZ LÓPEZ, J. M.; SANTIAGO PÉREZ, A.; FINLAYSON, G.; ALLUE, E.; BAENA PREYSLER, J.; CÁCERES, I.; CARRIÓN, J. S.; FERNÁNDEZ JALVO, Y.; GLEED-OWEN, C. P.; JIMENEZ ESPEJO, F. J.; LÓPEZ, P.; LÓPEZ SÁEZ, J. A.; RIQUELME CANTAL, J. A.; SÁNCHEZ MARCO, A.; GILES GUZMAN, F.; BROWN, K.; FUENTES, N.; VALARINO, C. A.; VILLALPANDO, A.; STRINGER, C. B.; MARTINEZ RUIZ, F.; SAKAMOTO, T.(2006) Late survival of Neanderthals at the southernmost extreme of Europe. Nature, 443 (7113), 2006, pp. 850-853 <https://doi.org/10.1038/nature05195>

- GARCÍA-AGUILAR, J. M.; GUERRA-MERCHÁN, A.; SERRANO, F.; PALMQVIST, P.; FLORES-MOYA, A.; MARTÍNEZ-NAVARRO, B. (2014) Hydrothermal activity and its paleoecological implications in the latest Miocene to Middle Pleistocene lacustrine environments of the Baza Basin (Betic Cordillera, SE Spain). Quaternary Science Reviews, vol. 96, 2014, pp. 204-221 <https://doi. org/10.1016/j.quascirev.2013.07.009>

- GARCÍA-AGUILAR, J. M.; GUERRA-MERCHÁN, A.; SERRANO, F.; FLORES-MOYA, A.; DELGADO-HUERTAS, A.; ESPIGARES, M. P.; ROS-MONTOYA, S.; MARTÍNEZNAVARRO, B.; PALMQVIST, P. (2015) A reassessment 
of the evidence for hydrothermal activity in the NeogeneQuaternary lacustrine environments of the Baza basin (Betic Cordillera, SE Spain) and its paleoecological implications. Quaternary Science Reviews, 112, 2015, pp. 226-235 <https://doi.org/10.1016/j.quascirev.2015.02.001>

- GARCÍA-MEDRANO, P.; CÁCERES, I.; OlLÉ, A.; CARBONELL, E. (2017) The occupational pattern of the Galería site (Atapuerca, Spain): A technological perspective. Quaternary International, vol. 433, 2017, pp. 363-378 <https://doi.org/10.1016/j.quaint.2015.11.013>

- GIBERT, J.; RIBOT, F.; GIBERT, L.; LEAKEY, M.; ARRIBAS, A.; MARTÍNEZ, B. (1995) Presence of the cercopithecid genus Theropithecus in Cueva Victoria (Murcia, Spain). Journal of Human Evolution, 28, 1995, pp. 487-493 <https://doi.org/10.1006/jhev.1995.1036>

- GILESPACHECO, F.; SANTIAGO,A.; GUTIÉRREZ, J. M.; LÓPEZ-GARCÍA, J. M.; BLAIN, H. A.; CUENCA-BESCÓS, G.; MADE, J. (DER); CÁCERES, I.; GARCÍA, N. (2011) The Early Pleistocene paleontological site in the Sierra del Chaparral (Villaluenga del Rosario, Cádiz, Southwestern Spain). Quaternary International, vol. 243, 2011, pp. 92-104 <https://doi.org/10.1016/j.quaint.2011.05.034>

- GÓMEZ DE SOLER, B.; CAMPENY VALL-LLOSERA, G.; MADE, J. (VAN DER); OMS, O.; AGUSTÍ, J.; SALA, R.; BLAIN, H. A.; BURJACHS, F.;CLAUDE, J.; GARCÍA CATALÁN, S.; RIBA, D.; ROSILLO, R. (2012) A new key locality for the Pliocene vertebrate record of Europe: the Camp dels Ninots maar (NE Spain). GeologicaActa 10, 2012, pp. 1-17 DOI: <http://dx.doi.org/10.1344/105.000001702>

- GUERRA-MERCHÁN, A.; RUIZ-BUSTOS, A.; MARTÍNPENELA, A. J. (1991) Geología y fauna de los yacimientos de Colorado 1, Colorado 2, Aljibe 2 y Aljibe 3 (Cuenca de Guadix-Baza, Cordilleras Béticas). Geogaceta, 9, 1991, pp. 99-102

- hORTOLÀ, P.; MARTínEZ-NAVARRO, B. (2013) The Quaternary megafaunal extinction and the fate of Neanderthals: An integrative working hypothesis. Quaternary International, vol. 295, 2013, pp. 69-72 <https:// doi.org/10.1016/j.quaint.2012.02.037>

- JIMÉNEZ-ARENAS, J. M.; SANTONJA, M.; BOTELLA, M.; PALMQVISTE, P. (2011) The oldest handaxes in Europe: fact or artefact? Journal of Archaeological Science, vol. 38, n. ${ }^{\circ} 12$, 2011, pp. 3340-3349 <https://doi.org/10.1016/j. jas.2011.07.020>

- KOUFOS, G.; KOSTOPOULOS, D. (1997) Biochronology and succession of the Plio-Pleistocene macromammalian localities of Greece. En AGUILAR, J. P.; LEGENDRE, J.; MICHEAUX, J. (ed.) Actes du Congrès Biochro M'97. Mémoires et Travaux de l'Institut de Montpellier (EPHE), 21, 1997, pp. 619-634
- KURTÉN, B.; CRUSAFONT PAIRÓ, M. (1977) Villafranchian Carnivores (Mammalia) from La Puebla de Valverde (Teruel, Spain). Helsinki: Societas Scientiarum Fennica, 1977, pp. 1-39 (Series Commentationes biologicae, 85)

- LACOMBAT, F.; ABBAZZI, L.; FERRETTI, M. P.; MARTÍNEZ-NAVARRO, B.; MOULLÉ, P. E.; PALOMBO, M. R.; ROOK, L.;TURNER, A.; VALLIG, A. M. F.(2008) New data on the Early Villafranchian fauna from Vialette (Haute-Loire, France) based on the collection of the Crozatier Museum (Le Puy-en-Velay, Haute-Loire, France). Quaternary International, vol. 179, n. ${ }^{\circ}, 2008$, pp. 64-71 <https://doi.org/10.1016/j.quaint.2007.09.005>

- LINDSAY, E. H.; OPDYKE, N. O.; JOHNSON, N. M. (1980) Pliocene dispersal of the horse Equus and late Cenozoic mammalian dispersal events. Nature, 287, pp. 135-138 doi:10.1038/287135a0

- MADURELL-MALAPEIRA, J.; MINWER-BARAKAT, R.; ALBA, D. M.;GARCÉS, M.; GÓMEZ, M.; AURELLGARRIDO, J.; ROS-MONTOYA, S.; MOYÀ-SOLÀ, S.; BERÁSTEGUIC, X.(2010) The Vallparadís section (Terrassa, Iberian Peninsula) and the latest Villafranchian faunas of Europe. Quaternary Science Reviews, vol. 29, n. ${ }^{\circ}$ 27-28, 2010, pp. 3972-3982 <https://doi.org/10.1016/j. quascirev.2010.09.020>

- MADURELL-MALAPEIRA, J.; ROS-MONTOYA, S.; ESPIGARES, M. P.; ALBA, D. M.; AURELL-GARRIDO, J. (2014) Villafranchian large mammals from the Iberian Peninsula: paleobiogeography, paleoecology and dispersal events. Journal of Iberian Geology [en línea], vol. 40, n. ${ }^{\circ} 1$, 2014, pp. 167-178 <http://revistas.ucm.es/index.php/JIGE/ article/view/44093/41692> [Consulta: 21/05/2018]

- MARIGÓ, J.; SUSANNA, I.; MINWER-BARAKAT, R.; MADURELL-MALAPEIRA, J.; MOYÀ-SOLÀ, S.; CASANOVAS-VILAR, I.; ROBLES, J. M.; ALBA, D.M. (2014) The primate fossil record in the Iberian Peninsula. Journal of Iberian Geology [en línea], vol. 40, n. ${ }^{\circ} 1,2014$, pp. 179-211 <http://revistas.ucm.es/index.php/JIGE/article/ view/44094> [Consulta: 21/05/2018]

- MARTÍN-PENELA, A. J. (1988) Los grandes mamíferos del yacimiento Achelense de la Solana del Zamborio, Fonelas (Granada, España). Antropología y Paleoecología Humana, n. ${ }^{\circ}$, 1988 , pp. 29-187

- MARTÍNEZ-NAVARRO, B. (2001) Prospección paleontológica con sondeo estratigráfico en el yacimiento de Baza-1 (Rusciniense Superior). Informe de las campañas correspondientes a los años 2000 y 2001 . Delegación de Cultura de Granada. Junta de Andalucía. Inédito

- MARTíNEZ-NAVARRO, B. (2010) Early Pleistocene faunas of Eurasia and hominin dispersals. En FLEAGLE, J. G.; SHEA, J. J.; GRINE, F. E.; BADEN, A. L.; LEAKEY, 
R. E. (ed.) Out of Africa I: The First Hominin Colonization of Eurasia. New York: Springer, 2010, pp. 207-224

- MARTÍNEZ-NAVARRO, B.; CLARET, A.; SHABEL, A. B.; PÉREZ-CLAROS, J. A.; LORENZO, C.; PALMQVIST, P. (2005) Early Pleistocene "hominid remains" from southern Spain and the taxonomic assignment of the Cueva Victoria phalanx. Journal of Human Evolution, 48 (5), 2005, pp. 517$523<$ https://doi.org/10.1016/j.jhevol.2005.02.003>

- MARTÍNEZ-NAVARRO, B.; MADURELL-MALAPEIRA, J.; ROS-MONTOYA, S.; ESPIGARES, M. P.; MEDIN, T.; HORTOLÀ, P.; PALMQVIST, P. (2015) The Epivillafranchian and the arrival of pigs into Europe. Quaternary International, vol. 389, 2015, pp. 131-138 <https://doi.org/10.1016/j. quaint.2015.09.039>

- MARTÍNEZ-NAVARRO, B.; PALMQVIST, P. (1995) Presence of the African Machairodont Megantereon whitei (Broom, 1937) (Felidae, Carnivora, mammalia) in the lower pleistocene site of Venta Micena (Orce, Granada, Spain), with some considerations on the origin, evolution and dispersal of the genus. Journal of Archaeological Science, 22, 1995, pp. 569-582

- MARTÍNEZ-NAVARRO, B.; PALMQVIST, P. (1996) Presence of the African saber-toothed felid Megantereon whitei (BROOM, 1937) (Mammalia, Carnivora, Machairodontidae) in Apollonia-1 (Mygdonia Basin, Macedonia, Greece). Journal of Archaeological Science, 23, 1996, pp. 869-872

- MARTÍNEZ-NAVARRO, B.; PALMQVIST BARRENA, P.; MADURELL-MALAPEIRA, J.; ROS MONTOYA, S.; ESPIGARES ORTIZ, M. P.; TORREGROSA, V.; PÉREZ CLAROS, J. A.(2010) La fauna de grandes mamíferos de Fuente Nueva-3 y Barranco León-5: Estado de la cuestión. En TORO, I.; MARTÍNEZ-NAVARRO, B.; AGUSTÍ, J. (coord.) Ocupaciones Humanas en el Pleistoceno Inferior y Medio de la Cuenca de Guadix-Baza. Sevilla: Junta de Andalucía, Consejería de Cultura, 2010, pp. 197-236

- MARTínEZ-NAVARRO, B.; PALMQVIST, P.; SHABEL, A. B.; CLARET DOS SANTOS, A. (2008) Reply to Gibert et al. (2008) on the supposed human phalanx from Cueva Victoria (Cartagena, Spain). Journal of Human Evolution, 54 (1), 2008, pp. 157-161

- MARTÍNEZ-NAVARRO, B.; PÉREZ-CLAROS, J. A.; PALOMBO, M. R.; ROOK, L.; PALMQVIST, P. (2007) The Olduvai buffalo Pelorovis and the origin of Bos. Quaternay Research, vol. 68, n. ${ }^{\circ} 2$, 2007, pp. 220-226 <https://doi. org/10.1016/j.yqres.2007.06.002>

- MARTÍNEZ-NAVARRO, B.; ROOK, L. (2003) Gradual evolution in the African hunting dog lineage. Systematic implications. Comptes Rendus Paléovol, vol. 2, n. ${ }^{\circ} 8,2003$, pp. 695-702 <https://doi.org/10.1016/j.crpv.2003.06.002>
- MARTÍNEZ-NAVARRO, B.; ROS-MONTOYA, S.; ESPIGARES, M. P.; PALMQVIST, P. (2011) Presence of the Asian origin Bovini, Hemibos sp. aff. Hemibos gracilis and Bison sp., at the early Pleistocene site of Venta Micena (Orce, Spain). Quaternary International, vol. 243, n. ${ }^{\circ} 2011$, pp. 54-60 <https://doi.org/10.1016/j.quaint.2011.05.016>

- MARTÍNEZ-NAVARRO, B.; TORO MOYANO, I.; ROSMONTOYA, S.; ESPIGARES ORTIZ, M. P.; FAJARDOFERNÁNDEZ-PALMA, B. (2006) Resultados de la Prospección Superficial del Área de Huéscar (Sector Nororiental de la Cuenca de Guadix-Baza), Campaña 2003. Anuario Arqueológico de Andalucía/2003. Sevilla: Dirección General de Bienes Culturales. Consejería de Cultura de la Junta de Andalucía, 2006, pp. 54-59

- MAZO, A. V. (1989) Nuevos restos de Proboscidea (Mammalia) en la cuenca de Guadix-Baza. En ALBERDI, M. T.; BONADONNA, F. (ed.) Geología y Paleontología de la cuenca de Guadix-Baza. Madrid: Museo Nacional de Ciencias Naturales CSIC, 1989, pp. 225-236 (Trabajos sobre el Neógeno-Cuaternario, vol. 11)

- MAZO, A. V. (1997) El yacimiento Rusciniense de Alcalá de Júcar (Albacete). Taxonomía y Bioestratigrafía. Estudios Geológicos, 53, 1997, pp. 275-286

- MAZO, A. V.; MADE, J. (VAN DER); ARRIBAS, A.; SÁNCHEZ, A. (2003) Hace 3 Millones de Años (Catálogo de la exposición). Ciudad Real: Fundación de Cultura y Deportes de Castilla La Mancha. Junta de Comunidades de Castilla-La Mancha

- FATÁS MONFORTE, P.; LASHERAS CORRUCHAGA, J. A.; RASINES DEL RÍO, P.; MONTES BARQUÍN, R.; HERAS MARTÍN, C. (DE LAS) (2004) Los "aerógrafos" de la Cueva de Altamira. Zona arqueológica, n. ${ }^{\circ}$ 4(4), 2004, miscelánea en homenaje a Emiliano Aguirre, pp. 320-327

- MORATORCAL, R.; MATEU, J.; CARBONELL I ROURA, E.; YLL, R.; GUSI JENER, F.; ESTÉVEZ ESCALERA, J. (1980) Avance preliminar sobre el yacimiento del Pleistoceno medio. Cova del Tossal de la Font (Vilafamés, Castellón). Cuadernos de Prehistoria y Arqueología, 7, 1980, p. 7 ss.

- MOYÀ-SOLÀ, S. (1987) Los bóvidos (Artiodactyla, Mammalia) del yacimiento del Pleistoceno inferior de Venta Micena (Orce, Granada, España). Paleontologia i Evolució, Mem. Esp., 1, 1987, pp. 181-236

- MOYÀ-SOLÀ, S.; AGUSTÍ, J.; MARÍN, M. (1987) Fuentesnuevas 1: nueva localidad con mamíferos del Plioceno superior de Guadix-Baza (Granada, España). Paleontologia i Evolució, Mem. Esp., 1, 1987, pp. 87-93

- PALMQVIST, P.; ARRIBAS, A. (2001) Taphonomic decoding of the paleobiological information locked in a lower 
Pleistocene assemblage of large mammals. Paleobiology, 27,2001 , pp. $512-530$

- PALMQVIST, P.; MARTÍNEZ-NAVARRO, B.; ARRIBAS, A. (1996) Prey selection by terrestrial carnivores in a lower Pleistocene paleocommunity. Paleobiology, 22, 1996, pp. 514-534

- PALMQVIST, P.; ARRIBAS, A.; MARTÍNEZ-NAVARRO, B. (1999) Ecomorphological study of large canids from the lower Pleistocene of southeastern Spain. Lethaia, 32, 1999, pp. $75-88$

- PALMQVIST, P.; GRÖCKE, D. R.; ARRIBAS, A.; FARIÑA, R. A. (2003) Paleoecological reconstruction of a lower Pleistocene large mammals community using biogeochemical $(\delta 13 \mathrm{C}, \delta 15 \mathrm{~N}, \delta 18 \mathrm{O}, \mathrm{Sr}: \mathrm{Zn})$ and ecomorphological approaches. Paleobiology, 29(2), 2003, pp. 205-229 <https://doi.org/10.1017/S0094837 300018078>

- PALMQVIST, P.; TORREGROSA, V.; PÉREZ-CLAROS, J. A.; MARTÍNEZ-NAVARRO, B.; TURNER, A. (2007) A re-evaluation of the diversity of Megantereon (Mammalia, Carnivora, Machairodontinae) and the problem of species identification in extinct carnivores. Journal of Vertebrate Paleontology, vol. 27, n. ${ }^{\circ}$ 1, pp. 160-175

- PALMQVIST, P.; PÉREZ-CLAROS, J.A.; JANIS, C. M.; GRÖCKE, D. R. (2008) Tracing the ecophysiology of ungulates and predator-prey relationships in an early Pleistocene large mammal community. Palaeogeography, Palaeoclimatology, Palaeoecology, vol. 266, n. ${ }^{\circ} 1-2,2008$, pp. 95-111 <https://doi.org/10.1016/j.palaeo.2008.03.015>

- PALMQVIST, P.; PÉREZ-CLAROS, J. A.; JANIS, C. M.; FIGUEIRIDO, B.; TORREGROSA, V.; GRÖCKE, D. R. (2008) Biogeochemical and ecomorphological inferences on prey selection and resource partitioning among mammalian carnivores in an early Pleistocene community. Palaios, 23 (11), 2008, pp. 724-737 DOI: <https://doi.org/10.2110/ palo.2007.p07-073r>

- PALMQVIST, P.; MARTÍNEZ-NAVARRO, B.; PÉREZCLAROS, J. A.; TORREGROSA, V.; FIGUEIRIDO, B.; JIMÉNEZ-ARENAS, J. M.; ESPIGARES, M. P.; ROSMONTOYA, S.; RENZIG, M. (DE) (2011) The giant hyena Pachycrocuta brevirostris: modeling the bone-cracking behavior of an extinct carnivore. Quaternary International, vol. 243 , n.o 1 , 2011, pp. $61-79$ < https://doi.org/10.1016/j. quaint.2010.12.035>

- PALMQVIST, P.; DUVAL, M.; DIÉGUEZ, A.; ROSMONTOYA, S.; ESPIGARES, M. P. (2016) On the fallacy of using orthogenetic models of rectilinear change in arvicolid teeth for estimating the age of the first human settlements in Western Europe. Historical Biology, vol. 28, n. ${ }^{\circ} 6,2016$, pp. 734-752 <https://doi.org/10.1080/08912963.2015.1025 390>
- PERETO, L. (1865) Note sur les subdivisions que l'on pourrait établir dans les terrains tertiaires de l'Apennin septentrional. Bulletin de la Société Gélogique de France, 22, pp. 210-277

- PIÑERO, P.; AGUSTÍ, J.; OMS, O.; BLAIN, H. A.; LAPLANA, C.; ROS-MONTOYA, S.; MARTÍNEZNAVARRO, B. (2017) Rodents from Baza-1 (GuadixBaza Basin, southeast Spain): filling the gap of the early Pliocene succession in the Betics. Journal of Vertebrate Paleontology, vol. 37, n. ${ }^{\circ} 4,2017$ <https://doi.org/10.1080 /02724634.2017.1338294>

- RADUlesCu, C.; SAMSON P. M.; PETCUlesCu, A.; STIUCA, E. (2003) Pliocene Large Mammals of Romania Grandes Mamíferos del Plioceno de Rumania. Coloquios de Paleontología, vol. Extra 1, 2003, pp. 549-558

- RODRÍGUEZ-GÓMEZ,G.;PALMQVIST,P.;RODRÍGUEZ, J.; MATEOS, A.; MARTÍN-GONZÁLEZ, J. A.; ESPIGARES, M. P.; ROS-MONTOYA, S.; MARTÍNEZ-NAVARRO, B. (2016) On the ecological context of the earliest human settlements in Europe: Resource availability and competition intensity in the carnivore guild of Barranco León-D and Fuente Nueva-3 (Orce, Baza Basin, SE Spain). Quatemary Science Reviews, vol. 143, pp. 69-83 <https:// doi.org/10.1016/j.quascirev.2016.05.018>

- ROOK, L.; MARTÍNEZ-NAVARRO, B. (2010) Villafranchian: the long story of a Plio-Pleistocene European large mammal biochronologic unit. Quaternary International, vol. 219, n. ${ }^{\circ} 1-2,2010$, pp. 134-144 <https:// doi.org/10.1016/j.quaint.2010.01.007>

- ROS-MONTOYA, S. (2006) El Padul (Granada): presencia de Mamut Lanudo (Mammuthus primigenius BLUMENBACH) en el Sur de España. Miscelánea Paleontológica. Publicaciones del Seminario de Paleontología de Zaragoza (SEPAZ), vol. 6, 2006, pp. 275293

- ROS-MONTOYA, S. (2010) Los Proboscídeos del PlioPleistoceno de las Cuencas de Guadix-Baza y Granada. Tesis doctoral inédita, Universidad de Granada, 403 pp.

- ROS-MONTOYA, S.; MADURELL-MALAPEIRA J.; MARTÍNEZ-NAVARRO, B.; ESPIGARES, M. P.; PALMQVIST, P. (2012) Late Villafranchian Mammuthus meridionalis (Nesti, 1825) from the Iberian Peninsula: Dentognathic remains from Incarcal-I (Crespià, Girona) and Venta Micena (Orce, Granada). Quaternary International, vol. 276-277, 2012, pp. 17-22 <https://doi.org/10.1016/j. quaint.2012.03.007>

- ROS-MONTOYA, S.; MARTÍNEZ-NAVARRO, B. ESPIGARES, M. P.; GUERRA-MERCHÁN, A.; GARCÍAAGUILAR, J. M.; PIÑERO, P.; RODRÍGUEZ-RUEDA, A.; AGUSTÍ, J.; OMS, O.; PALMQVIST, P. (2017) A new Ruscinian site in Europe: Baza-1 (Baza basin, Andalusia, 
Spain). Comptes Rendus Palevol, vol. 16, n. ${ }^{\circ}$ 7, 2017, pp. 746-761 <https://doi.org/10.1016/j.crpv.2017.05.005>

- ROS-MONTOYA, S.; MARTÍNEZ-NAVARRO, B. ESPIGARES, M. P.; PALMQVIST, P. (2016) Fuente Nueva 1: el registro más antiguo del Pleistoceno inferior de Orce. En MELÉNDEZ, G.; NúÑ̃EZ, A.; TOMÁS, M. (ed.) Actas de las XXXII Jornadas de la Sociedad Española de Paleontología. Madrid: Instituto Minero y Geológico de España, 2016, pp. 387-391 (Cuadernos del Museo Geominero, 20)

- ROSAS, A.; MARTÍNEZ-MAZA, C.; BASTIR, M.; GARCÍA-TABERNERO, A.; LALUEZA-FOX, C.; HUGUET, R.; EUGENIO ORTIZ, J.; JULIÀ, R.; SOLER, V.; TORRES, T. (DE); MARTÍNEZ, E.; CAÑAVERAS, J. C.; SÁNCHEZMORAL, S.; CUEZVA, S.; LARIO, J.; SANTAMARÍA, D.; RASILLA, M. (DE LA); FORTEA, J. (2006) Paleobiology and comparative morphology of a late Neandertal sample from El Sidrón, Asturias, Spain. PNAS, 103 (51), 2006, pp. 19266-19271 <https://doi.org/10.1073/pnas.0609662104>

- RUIZ BUSTOS, A. (1976) Estudio sistemático y ecológico sobre las faunas del Pleistoceno Medio en las depresiones granadinas. El yacimiento de Cúllar de Baza I. Tesis doctoral. Universidad de Granada. Facultad de Ciencias. Trabajos y Monografía, 1, pp. 1-300

- RUIZ-BUSTOS, A. (1999) Biostratigraphy of the continental deposits in the Granada, Guadix and Baza basins (Betic Cordillera). En GIBERT, J.; SÁNCHEZ, F.; GIBERT, L.; RIBOT, F. (ed.) The hominids and their environment during the Lower and Middle Pleistocene of Eurasia. Orce (Granada): Ayuntamiento, Museo de Prehistoria y Paleontología "J. Gibert", 1999, pp. 153174

- SANTONJA GÓMEZ, M.; PÉREZ GONZÁlEZ, A.; RUIZ ZAPATA, B.; SESÉ, C.; SOTO, E. (2005) Esperando el Diluvio. Ambrona y Torralba hace 400.000 años. Madrid: Museo Arqueológico Regional, Comunidad de Madrid, Junta de Castilla y León, 2005

- SAÑUDO, P.; BLASCO, R.; FERNÁNDEZ PERIS, J. (2016) Site formation dynamics and human occupations at Bolomor Cave (Valencia, Spain): An archaeostratigraphic analysis of levels I to XII (100-200 ka). Quaternary International, vol. 417, 2016, pp. 94-104 <https://doi. org/10.1016/j.quaint.2015.09.044>

- SCOTT, G. R.; GIBERT, L. (2009) The oldest handaxes in Europe. Nature, 461, 2009, pp. 82-85 doi:10.1038/ nature08214

- SEQUEIROS, L. (2011) Elefantes, tortugas y volcanes. aLCOLEA DE CALATRAVA Y SUS FÓSILES. Madrid: Bubok Publishing, 2011

- SINUSIA, C.; PUEYO, E. L.; AZANZA, B.; POCOVI, A. (2004) Datación magnetoestratigráfica del yacimiento paleontológico de la Puebla de Valverde (Teruel). Geotemas, 6, 2004, pp. 329-342

- STEELMAN, K. L.; LOMBERA HERMIDA, A. (DE); VIÑAS VALLVERDÚ, R.; RODRÍGUEZ-ÁLVAREZ, X. P.; CARRERA-RAMÍREZ, F.; RUBIO-MORA, A.; FÁBREGASVALCARCE, R. (2017) Cova Eirós: an integrated approach to dating the earliest known cave art in NW Iberia. Radiocarbon, vol. 59, n. ${ }^{\circ}$ 1, 2017, pp. 151-164 <https://doi. org/10.1017/RDC.2017.4>

- TORO-MOYANO, I.; MARTÍNEZ-NAVARRO, B.; AGUSTÍ, J.; SOUDAY, C.; BERMÚDEZ DE CASTRO, J. M.; MARTINÓN-TORRES, M.;. FAJARDO, B; DUVAL, M.; FALGUĖRES, C.; OMS, O.; PARÉS, J. M.; ANADÓN P.; JULIÀ, R.; GARCÍA-AGUILAR, J. M.; MOIGNE, A. M.; ESPIGARES, M. P.; ROS-MONTOYA, S.; PALMQVIST, P. (2013) The oldest human fossil in Europe, from Orce (Spain). Journal of Human Evolution, vol. 65, n. ${ }^{\circ}$ 1, 2013, pp. 1-9

- VALLVERDÚ, J.; SALADIÉ, P.; ROSAS, A.; HUGUET, R.; CÁCERES, I.; MOSQUERA, M.; GARCIA-TABERNERO, A.; ESTALRRICH, A.; LOZANO-FERNÁNDEZ, I.; PINEDAALCALÁ, A.; CARRANCHO, A.; VILLALAÍN, J. J.; BOURLÈS, D.; BRAUCHER, R.; LEBATARD, A.; VILALTA, J.; ESTEBAN-NADAL, M.; BENNÀSAR, M. L.; BASTIR, M.; LÓPEZ-POLÍN, L.; OLLÉ, A.; VERGÉS, J. M.; ROSMONTOYA, S.; MARTÍNEZ-NAVARRO, B.; GARCÍA, A.; MARTINELL, J.; EXPÓSITO, I.; BURJACHS, F.; AGUSTÍ, J.; CARBONELL, E. (2014) Age and Date for Early Arrival of the Acheulian in Europe (Barranc de la Boella, la Canonja, Spain). PlosONE 9(7): e103634. <https://doi.org/10.1371/ journal.pone.0103634>

- VEGA-TOSCANO G.; HOYOS M.; RUIZ-BUSTOS A.; LAVILLE, J. (1988) La séquence de la grotte de la Carihuela (Pinar, Grenade): chronostratigraphie et paléoécologie du Pléistocène supérieur au sud de la péninsule ibérique. En OTTE, M. (ed.) L'Homme de Néandertal. L'Environnement. Liège: Université de Liège, p1988, p. 169-180

- VICENTE GABARDA, V.; MARTÍNEZ VALLE, R.; GUILLEM CALATAYUD, M.; GARAY MARTÍ, P.; PUEYO, E.; CASABÓ, J. (2016) The Lower Palaeolithic site Alto de las Picarazas (Andilla-Chelva, Valencia). Quaternary International, vol. 393, 2016, pp. 83-94 <https://doi. org/10.1016/j.quaint.2015.04.049>

- VILLALTA, J. F.; LLOMPART, C. (1981) Hallazgo de un molar de Mammut borsoni (Hays) en el Plioceno del Baix Empurdà (Prov. Girona). Acta Geológica Hispánica, 16, 1981, pp. 195-197

- WALKER, M. J.; GIBERT, J.; LÓPEZ, M. V.; VINCENT LOMBARDI, A.; PÉREZ-PÉREZ, A.; ZAPATA, J.; ORTEGA, J.; HIGHAM, T.; PIKE, A.; SCHWENNINGER, J. L.; ZILHÃO, J.; TRINKAUS, E. (2008) Late Neandertals in 
Southeastern Iberia: Sima de las Palomas del Cabezo Gordo, Murcia, Spain. PNAS [en línea], 105 (52), 2008, pp. 20631-20636 <http://www.pnas.org/content/105/52/20631> [Consulta: 22/05/2018]

- WALKER, M. J.; LÓPEZ-MARTÍNEZ, M.; CARRIÓNGARCÍA, J. S.; RODRÍGUEZ-ESTRELLA, T.; SANNICOLÁS DEL-TORO, M.; SCHWENNINGER, J. L.; LÓPEZ JIMÉNEZ, A.; ORTEGA-RODRIGÁÑEZ, J.; HABER-URIARTE, M.; POLO-CAMACHO, J. L.; GARCÍATORRES, J.; CAMPILLO-BOJ, M.; AVILÉS-FERNÁNDEZ, A.; ZACK, W.(2013) Cueva Negra del Estrecho del Río Quípar (Murcia, Spain): A late Early Pleistocene hominin site with an "Acheulo-Levalloiso-Mousteroid Palaeolithic assemblage. Quaternary International, 294, pp. 135-159 <https://doi.org/10.1016/j.quaint.2012.04.038> 